\title{
Las comarcas centromeridionales valencianas en el contexto de la Neolitización de la fachada noroccidental del Mediterráneo (1)
}

\author{
The Central Valencian region in the context of the Neolithisation of the North-Western \\ Mediterranean facade
}

Gabriel García Atiénzar (*)

\section{RESUMEN}

El proceso de neolitización de la fachada mediterránea peninsular se ha asociado tradicionalmente al paradigma cardial del ámbito franco-ibérico. No obstante, el mejor conocimiento del registro material del arco noroccidental mediterráneo, la revisión de diversos conjuntos arqueológicos de las comarcas centromeridionales valencianas y la observación de los patrones de ocupación y explotación del territorio en el Mediterráneo occidental permiten proponer un proceso de implantación neolítica más complejo del considerado hasta ahora que se puede enlazar con el mundo de la ceramica impressa mediterránea.

\begin{abstract}
The process of neolithisation of the Mediterranean facade of the Iberian Peninsula has traditionally been associated with the cardial paradigm of the french-iberian region. However, better knowledge of the material record from the north-western Mediterranean arc, the revision of various archaeological sites of the central Valencian region and observation of the patterns of occupation and exploitation of territory in the western Mediterranean allow us to propose a process of Neolithic introduction that is more complex than previously thought and be linked with the world of the Mediterranean impressed pottery.
\end{abstract}

(*) Área de Prehistoria. Universidad de Alicante. Dirección: Apdo. Correos 99. E-03080 Alicante. Correo electrónico: g.garcia@ua.es

Recibido: 15-VII-2009; aceptado: 3-XI-2009.

(1) Este trabajo supone un extracto revisado y actualizado de la Tesis Doctoral "La neolitización del territorio: el poblamiento neolítico en el área central del Mediterráneo español" que fue defendida en la Universidad de Alicante el 20 de junio de 2007.
Palabras clave: Neolítico; Cerámica impresa; Mediterráneo noroccidental; Agricultura.

Key words: Neolithic; Impressed pottery; north-western Mediterranean; Agriculture.

\section{INTRODUCCIÓN}

En las últimas décadas, el paradigma difusionista se ha ido consolidando como marco teórico para la explicación de la aparición de las primeras evidencias neolíticas en el Mediterráneo occidental (Zilhão 1993, 1997, 2001; Bernabeu 1996, 2006). Descartada la posibilidad de un proceso autóctono de transformación socio-económica ante la ausencia en esta región de los agriotipos y cultígenos silvestres de las especies domésticas protagonistas del proceso, en los últimos años la discusión ha girado en torno a cuestiones tales como las vías y mecanismos de la difusión, la interacción entre las comunidades neolíticas alóctonas y las poblaciones locales, el papel de estas últimas como receptoras o transmisoras de las innovaciones neolíticas o el ritmo de este proceso de colonización inicial. En este sentido, los trabajos de J. Zilhão (1993, 1997, 2001) sobre la difusión neolítica en la vertiente occidental mediterránea han planteado una velocidad mayor para este proceso de expansión demográfica que la esbozada tradicionalmente (Ammerman y Cavalli-Sforza 1973, 1984), apostando por una colonización marítima que tendría como resultado la neolitización de diferentes focos del Mediterráneo occidental en una horquilla cronológica de poco más de medio milenio. Asimismo, este mis- 
mo autor plantea que este proceso expansivo no sería homogéneo en el espacio pues afectaría de manera desigual a distintas regiones de las costas mediterráneas, generándose "vacíos de neolitización" en diferentes zonas lo que reforzaría el concepto de colonización marítima. Este proceso, entendido como un desarrollo de corta duración según atestiguan las fechas radiocarbónicas concentradas en una horquilla entre 6200 y $5500 \mathrm{cal}$ BC (Zilhão 2001: 14184), se determina por la presencia de diversos elementos que conforman el llamado paquete neolítico que ofrece características homogéneas desde las costas surorientales de la Península Itálica hasta la región central de Portugal, aunque cabe considerar también otras cuestiones como la posibilidad del papel de catalizador jugado por el norte de África en la neolitización del área meridional de Andalucía y Portugal (Manen et al. 2007).

No obstante, y a pesar de la rapidez y la aparente homogeneidad de esta difusión, pueden observarse diferencias que afectan a elementos que van desde el registro arqueológico hasta los sistemas socioeconómicos, incluyendo también los patrones de asentamiento. Estas diferencias, visibles en el gradiente cronológico Este-Oeste que caracteriza la difusión del Neolítico, quedan particularmente plasmadas en el registro cerámico pudiéndose distinguir diversas facies asociadas a otros tantos neolíticos antiguos que se atestiguan en las costas del Mediterráneo centro-occidental (Manen 2000, 2002). Asimismo, el análisis y descripción de los modelos de asentamiento durante el Neolítico antiguo en la cuenca noroccidental del Mediterráneo también pone de manifiesto una gran diversidad de situaciones reflejo de las múltiples variables que influyeron en la neolitización de estas tierras. El origen de estas divergencias puede rastrearse a partir del análisis de cuestiones tales como las imposiciones asociadas al contexto ambiental, la tradición socioeconómica del grupo que se asienta, el bagaje cultural, las relaciones establecidas con el sustrato mesolítico local, los elementos de índole social e ideológica o los diferentes lugares de origen.

\section{FACIES CERÁMICAS Y MODELOS DE GESTIÓN DEL TERRITORIO EN EL ÁMBITO NOROCCIDENTAL MEDITERRÁNEO}

En diversos trabajos, C. Manen (2000, 2002, 2007) ha propuesto la existencia de diversas fa- cies para el Neolítico antiguo de la región comprendida entre el Ródano y el Ebro atendiendo a las diferencias mostradas por los patrones decorativos de la cerámica en diversos yacimientos de la zona. Esta autora determina una fase inicial o pionera previa al desarrollo del horizonte cardial clásico compuesta por diversas facies que ofrecen un panorama caracterizado por un notable polimorfismo que se explicaría por la diversidad de procesos de neolitización y por la variedad de influencias culturales que convergen en la zona. Este complejo panorama encuentra su mejor reflejo en una serie de enclaves costeros localizados en el arco noroccidental del Mediterráneo, desde el Tirreno central hasta el Languedoc.

La neolitización del Tirreno se produce entre el 5900 y el $5200 \mathrm{cal} \mathrm{BC}$, aunque las dataciones muestran una mayor concentración en torno al 5600 cal BC (Grifoni 2001: 424), momento que se vincula con el predominio del llamado cardial tirrénico. Sin embargo, las dataciones más antiguas, no exentas de problemas de muestra (Fugazzola 2002), se corresponden con las ofrecidas por contextos arqueológicos vinculados al llamado estilo Guadone, característico del Neolítico antiguo evolucionado de Italia meridional (Fugazzola 2002; Manen y Sabatier 2003). En este momento de ocupación inicial, los asentamientos tienden a localizarse en torno a la línea de costa y las islas del archipiélago, aunque también se han documentado puntuales penetraciones hacia la Toscana o las áreas lacustres del Lacio septentrional (Fugazzola et al. 2003). Por otra parte, la escasez de datos referidos a las zonas costeras del Lacio se asocia a la existencia de amplias zonas palúdicas, aunque la presencia en esta región de asentamientos como Pyrgi o Palidoro podría estar apuntando hacia una pérdida de información a causa de cambios geomorfológicos (Manfredini 2002: 177), hecho que abre la posibilidad de un poblamiento más intenso del registrado actualmente.

Son las pequeñas islas situadas frente a las costas peninsulares las que aportan las evidencias estratigráficas más sólidas, algunas de las cuales se han vinculado con el Neolitico impresso de Italia meridional, lo cual supone la existencia de una facies previa al desarrollo del cardial tirrénico. En este sentido, uno de los referentes para explicar esta presencia pionera en el Tirreno se localiza en el yacimiento de Le Secche (isla de Giglio) (Ducci 2000). Este asentamiento, ubicado bajo un 
abrigo rocoso, aportó gran cantidad de materiales entre los que destacan la abundancia de productos de talla, caracterizados por la tendencia al microlitismo (trapecios), y el empleo de cuarzo local y materias importadas como obsidiana y sílex. Las particularidades de la industria lítica pulimentada apuntan, de manera indirecta, a la existencia de prácticas agrícolas, aunque no se desestima la recolección de moluscos como principal base económica (Brandaglia 2000: 131). Sin embargo, es el registro cerámico el que mejor define esta ocupación a nivel cronológico al haberse documentado varios fragmentos con decoración impresa formando motivos simples y repetitivos y con una disposición geométrica que ocupa todo el vaso, sintaxis que encuentra sus mejores paralelos en Italia meridional (facies Guadone), pero también en la zona ligur (Arene Candide, Arma dell'Aquila, Arma di Nassino o Grotta Pollera) y Francia meridional (Pont de Roque-Haute) (Fig. 1).

Pero esta presencia de elementos propios de la ceramica impressa de Italia meridional no es exclusiva de los contextos tirrénicos sino que también se advierte en el arco ligur-provenzal, aunque la variabilidad advertida en esta segunda región refleja un panorama extraordinariamente complejo.

Una de las facies identificadas para el Neolítico antiguo de este ámbito es la caracterizada por el empleo de la técnica decorativa sillon d'impre-
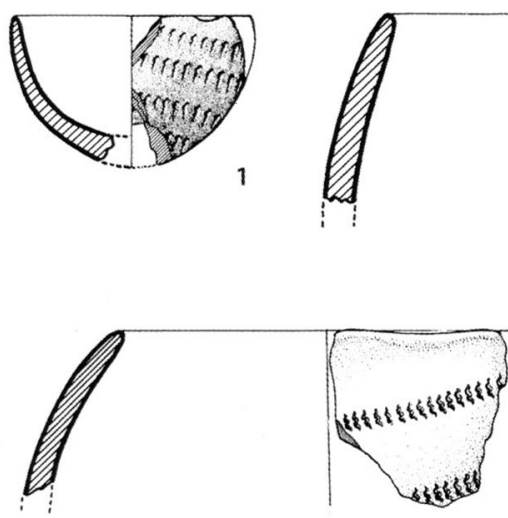
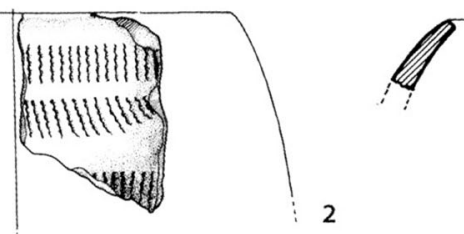

2

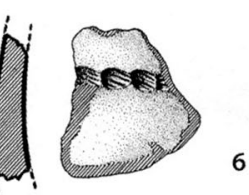

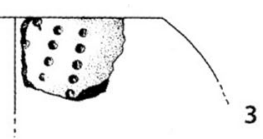

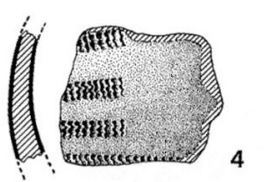

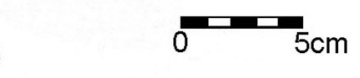

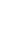
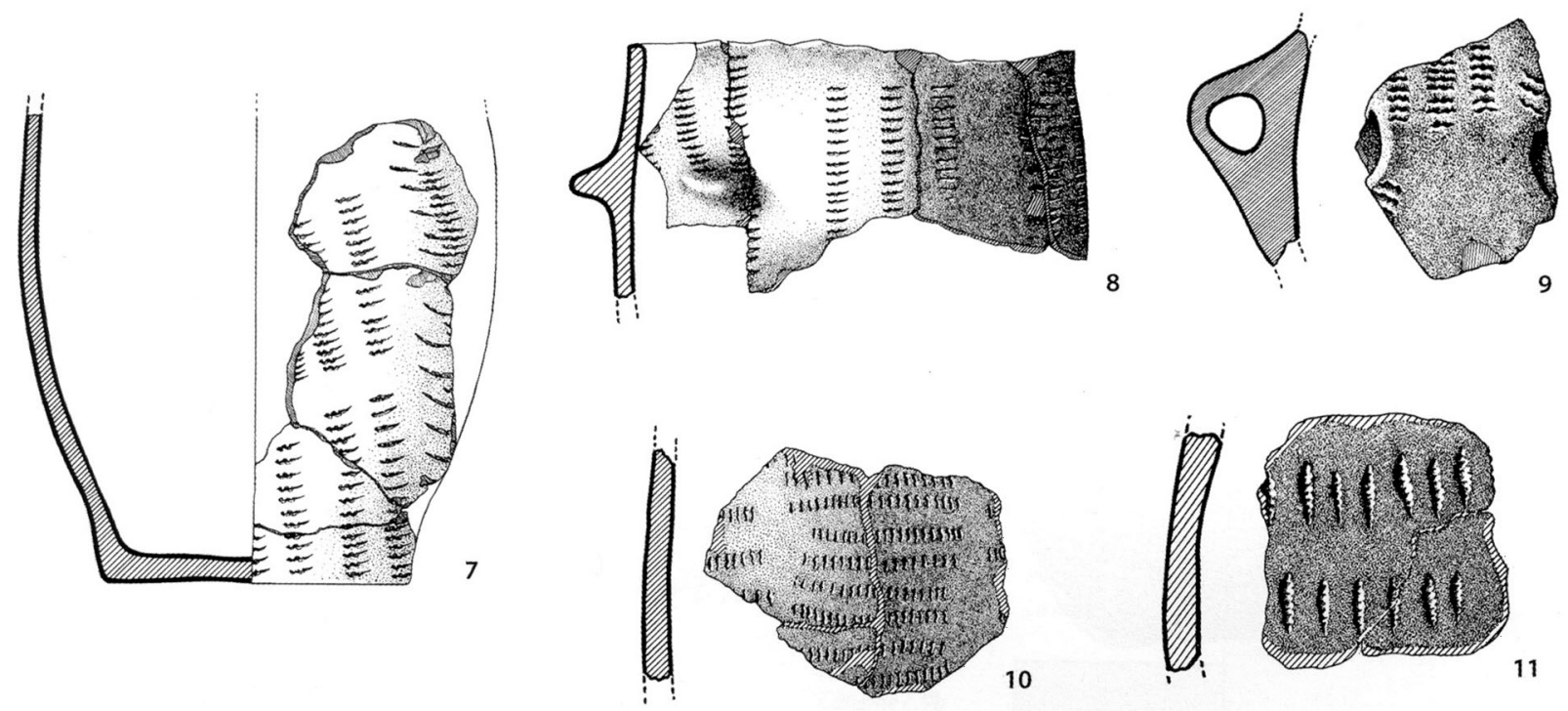

Fig. 1. Cerámica impresa de la isla de Giglio (Brandaglia 1991).

T. P., 67, N. ${ }^{\circ}$ 1, enero-junio 2010, pp. 37-58, ISSN: 0082-5638 doi: $10.3989 /$ tp. 2010.10030 
ssions (2), tipo que se documentó inicialmente en diversos yacimientos del arco ligur-provenzal entre los que cabe destacar varias cavidades de Finale Ligure (Savona): Arene Candide, Grotta dell'Edera, Arma dell'Aquila, Grotta Pollera, Arma di Nasino y otros yacimientos como Arma dello Stefanin (Val Pennavaira-Albenga), Caucade niv. 7-8 (Niza), Station du magazín de Giaume (Beaulieu-sur-Mer) o Station Sans-Peur (Grasse), asentamientos que sirvieron para dar origen al calificativo Ligurien (Roudil 1990). Posteriormente, esta facies fue identificada en varios sitios del Languedoc: Peiro Signado (Portiragnes, Hérault), Grotte de Bize (Bize, Aude), Grotte des Fées (Leucate, Aude), etc. (Binder 1989), considerándose en esta última región como una fase intrusiva vinculada al Neolítico antiguo de Liguria (Binder 1995; Manen 2000).

Esta facies cultural supone una ruptura con los complejos cardiales franco-ibéricos no sólo a nivel de sintaxis y técnica en la decoración cerámica, sino también por lo que respecta a la industria lítica, caracterizada en estos contextos por la producción de láminas regulares con talón facetado, el empleo de la talla por presión y la presencia de obsidiana del ámbito tirrénico (Briois 2005: 271). Estas divergencias también se dejan notar en los patrones económicos, centrados aquí en la cría de la oveja y el cultivo del Triticum dicoccum, variedad esta última poco representada en la región franco-ibérica y más habitual en el ámbito de la Italia meridional.

C. Manen (2000) mantuvo en primera instancia que podría tratarse de un fenómeno paralelo al cardial, aunque las dataciones obtenidas para los niveles 10 (Beta-110542: $6830 \pm 40 \mathrm{BP}-5790 / 5660 \mathrm{cal}$

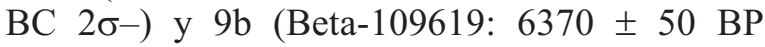
$-5480 / 5290$ cal BC $2 \sigma-$ ) de Arene Candide (Binder y Maggi 2001: 417) y para otros yacimientos del arco ligur-provenzal (Manen y Sabatier 2003: 498-499) permiten situar esta facies en un punto inmediatamente posterior a las primeras manifestaciones neolíticas de Italia meridional y, por lo tanto, anterior al desarrollo del horizonte cardial clásico.

(2) Esta técnica decorativa se obtiene apoyando una punta simple de extremo redondeado o anguloso en sentido más o menos inclinado y desplazándola en pequeños saltos sucesivos, obteniéndose una línea puntillada discontinua. Esta secuencia de surcos con sección en "U", especialmente apta para fijar colorante, se dispone formando motivos geométricos cubrientes: bandas, zigzags, impresiones cortas, impresiones más largas formando motivos triangulares y otros motivos que van desde el borde hasta el cuerpo (Roudil 1990: 386).
El yacimiento de Arene Candide (Finale Ligure, Savora) supone uno de los mejores referentes para explicar la implantación y posterior desarrollo de las primeras sociedades productoras en el arco ligur-provenzal. En los niveles 10 y $9 \mathrm{~b}$ base se reconoce una facies antigua, impressa ligur o Ligurien, caracterizada por el predominio de decoración instrumental a sequenza (sillon d'impressions) (Maggi 2002: 94) que parece tener sus orígenes en la Península Itálica y que se separa del fenómeno cardial tirrénico (3) que se desplegará posteriormente en la región. La reinterpretación de los resultados obtenidos para estas capas, niveles sedimentológicos 27-25 de la excavación de L. Bernabó (Maggi 1997) y 14-15 de la de S. Tiné (1999), ofrecen una imagen caracterizada por la explotación intensiva de los recursos marinos, en especial de conchas de Patella y Monodonta, que parece estar relacionada con amplias zonas de cocción en el sector oriental de la cavidad. Junto a estos restos malacológicos, la fauna doméstica es el otro gran recurso alimenticio. Se trata de una cabaña dominada por ovicápridos (con un claro predominio de la oveja) cuya cría podría ir ligada a la obtención de productos secundarios y, en menor medida, carne como parece desprenderse de la edad de sacrificio que ronda los 24 / 30 meses (Sorrentino 1999). El resto de la cabaña doméstica está compuesta por bóvidos, suidos y perro, aunque sin alcanzar los niveles mostrados por los ovicápridos. Por otra parte, la caza no parece ser un recurso importante durante esta primera fase. A estas evidencias cabe unir la existencia de diversas estructuras excavadas en el sedimento del horizonte más antiguo, en concreto varios agujeros de planta circular, interpretados como huellas de poste que se asocian a una estructura elevada, y varios hogares que suponen el primer suelo de ocupación neolítica de la cavidad. Estos datos permiten considerar un uso mixto de la cavidad como lugar de hábitat y actividades relacionadas con la transformación de los alimentos y como lugar en el que guardar el rebaño según se desprende de la presencia de todos los restos esqueléticos y de dientes de leche en el yacimiento. Este tipo de ocupación concuerda con los datos arrojados por la micromorfología (Macphail et al. 1997) que abogan por una pre-

(3) También definido como geométrico o estilo Basi-Pienza-Filiestru y que se desarrolla en el ámbito de Provenza oriental, Liguria y las costas e islas tirrénicas. 
sencia humana prolongada a lo largo del año aunque separada por intervalos.

El yacimiento que ha permitido caracterizar la facies sillon d'impression en el Languedoc es el de Peiro Signado (Portiragnes, Hérault). Este asentamiento, definido por la presencia de varias fosas en forma de cubeta excavadas en el sustrato geológico, se extiende a lo largo de una pequeña colina dominando la desembocadura del río Orb a tan sólo $2 \mathrm{~km}$ de la costa (Roudil y Soulier 1983; Brois 2005). El registro cerámico se caracteriza por un número limitado de formas, básicamente globulares simples de diferente diámetro, documentándose también varios fondos planos. Los motivos decorativos aparecen estructurados formando varios tipos: zigzag simples horizontales, triángulos delimitados, bandas de zigzag entre zonas delimitadas, líneas irregulares obtenidas por digitación o ungulación y bandas, sobre todo verticales y oblicuas, no delimitadas, temas que se documentan aislados o combinados entre sí en un mismo vaso. La técnica decorativa más habitual es la de sillon d'impressions, aunque también están presentes otras como la impresión mediante instrumento de punta compuesta: peine, espátula, etc. o la decoración impresa cardial. Este registro decorativo encuentra su mejor acomodo en los niveles 27-27 / 14-15 de Arene Candide, donde también predomina la técnica de sillon d'impressions con motivos largos y profundos dispuestos en zigzag. La industria lítica se fundamenta, básicamente, en el empleo de materias primas locales, aunque con una pequeña proporción de obsidiana de origen tirrénico (Lípari). Se caracteriza, además, por el fuerte predominio de la talla laminar, el empleo de la presión y la abundancia de soportes laminares con retoques laterales y trapecios simétricos con retoque abrupto y truncaduras rectilíneas (Roudil y Soulier 1983; Briois 2005), características también determinadas en el Tirreno (La Marmotta), donde prevalecen los trapecios isósceles con retoque abrupto y cuyas producciones líticas emplean la obsidiana como una de las materias primas más habituales (Fugazzola y Pessina 1999). En lo económico, los restos faunísticos son extraordinariamente escasos debido a la acidez del sedimento, habiéndose documentado tan sólo un reducido conjunto de dientes de ovicápridos, restos de dorada y varias conchas marinas. Por otro lado, las prácticas agrícolas están determinadas de manera directa a través de varios restos de Triticum dicoccum, además de otros pertenecientes a Triticum $\mathrm{sp}$. y Hordeum sp. (Fig. 2).
La facies cerámica representada por el yacimiento de Pont de Roque-Haute (Portiragnes, Hérault) no concuerda estrictamente con los esquemas decorativos del horizonte sillon d'impressions, presentando mayores similitudes con el archipiélago toscano, principalmente con la isla de Giglio (Manen 2007). La decoración de los vasos cerámicos se realiza mediante líneas de impresiones equidistantes, horizontales o verticales, con concha de Cardium, líneas de impresiones $a$ sequenza y líneas simples realizadas mediante impresiones varias, motivos en los que, además, no se observa geometrización. Esta autora plantea la hipótesis de posibles contactos entre la población del golfo de Génova y las poblaciones cardiales dando lugar a un estilo híbrido entre el cardial tirrénico y el Neolítico antiguo facies sillon d'impressions, pudiendo corresponderse con una facies particular del Neolítico antiguo de Italia no muy bien definida, pero que guarda similitud con la cerámica de la isla de Giglio y que cronológicamente habría que situar entre 5750-5500 cal BC (Manen 2002: 153). El resto del registro ar-
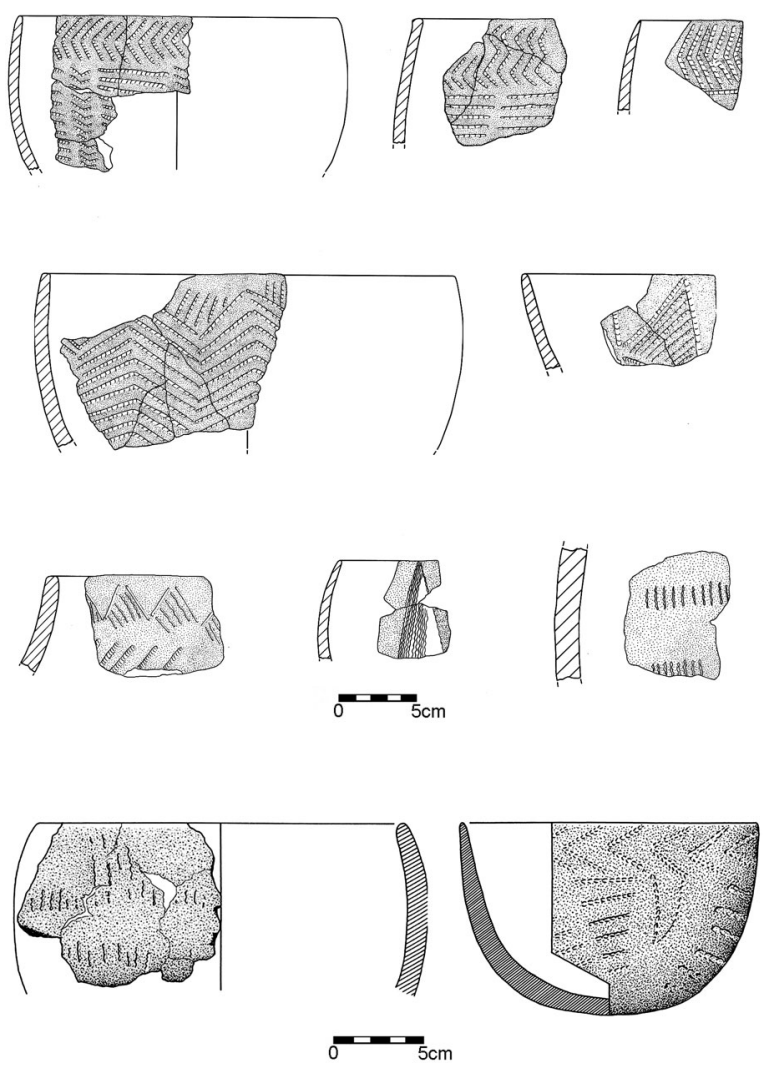

Fig. 2. Cerámica a sillon d'impressions de Peiro Signado (Manen 2002).

T. P., 67, N. $^{\circ} 1$, enero-junio 2010 , pp. $37-58$, ISSN: 0082-5638 doi: $10.3989 /$ tp.2010.10030 
queológico también denota fuertes relaciones con la región meridional italiana aunque, en este caso, el ambiente tirrénico parece jugar el papel más determinante, estableciéndose un claro vínculo con esta última región a partir de la presencia en ambas zonas de la talla por presión, la práctica de la fragmentación por microburil o la elaboración de trapecios con truncaduras rectas, características éstas que también habían sido determinadas para Peiro Signado. Otro elemento de unión sería la determinación de obsidiana procedente de la isla de Palmarola.

Las evidencias paleoeconómicas de Pont de Roque-Haute permiten inferir una ocupación estable durante todo el año (Vigne y Carrère 2007: 205). La cría de ovicaprinos ofrece un predominio casi absoluto con porcentajes situados cerca del $70 \%$ del total de restos de mamíferos, situación que enlaza este yacimiento con prácticas ganaderas propias de la región suroriental italiana y la Grecia adriática (Vigne 2007: 276). Dentro de este apartado, otro elemento que vincula este yacimiento con la región tirrénica son las características morfométricas del ganado ovino que acercan los restos de Pont de Roque-Haute a los patrones ob- servados en los yacimientos italo-tirrénicos y los separan de las características observadas en su contexto regional (Vigne 2007: 277). Esta cría especializada estaría complementada por la de suidos y bóvidos, aunque con un papel muy residual. Las prácticas cinegéticas son minoritarias, pero reflejan el aprovechamiento de diversos entornos medioambientales como el bosque (ciervo), espacios abiertos (liebre) e, incluso, ambientes lacustres interiores (tortuga terrestre), sistema que se ha relacionado con una actividad oportunista y diversificada como forma de paliar posibles malos resultados en la producción principal e, incluso, con motivaciones no exclusivamente alimenticias. La explotación del medio marino también juega un papel reseñable, aunque J.D. Vigne e I. Carrère (2007) recalcan la difícil estimación de su importancia. Con este tipo de entorno se relaciona la presencia de dorada, que permite hablar de una pesca costera, y de diversos moluscos marinos, principalmente de especies de entornos rocosos. A estas evidencias cabe unir la documentación de hasta 12 estructuras amortizadas como basureros, aunque no se pudo determinar si se trataban de estructuras asociadas a contextos de hábitat (Fig. 3).

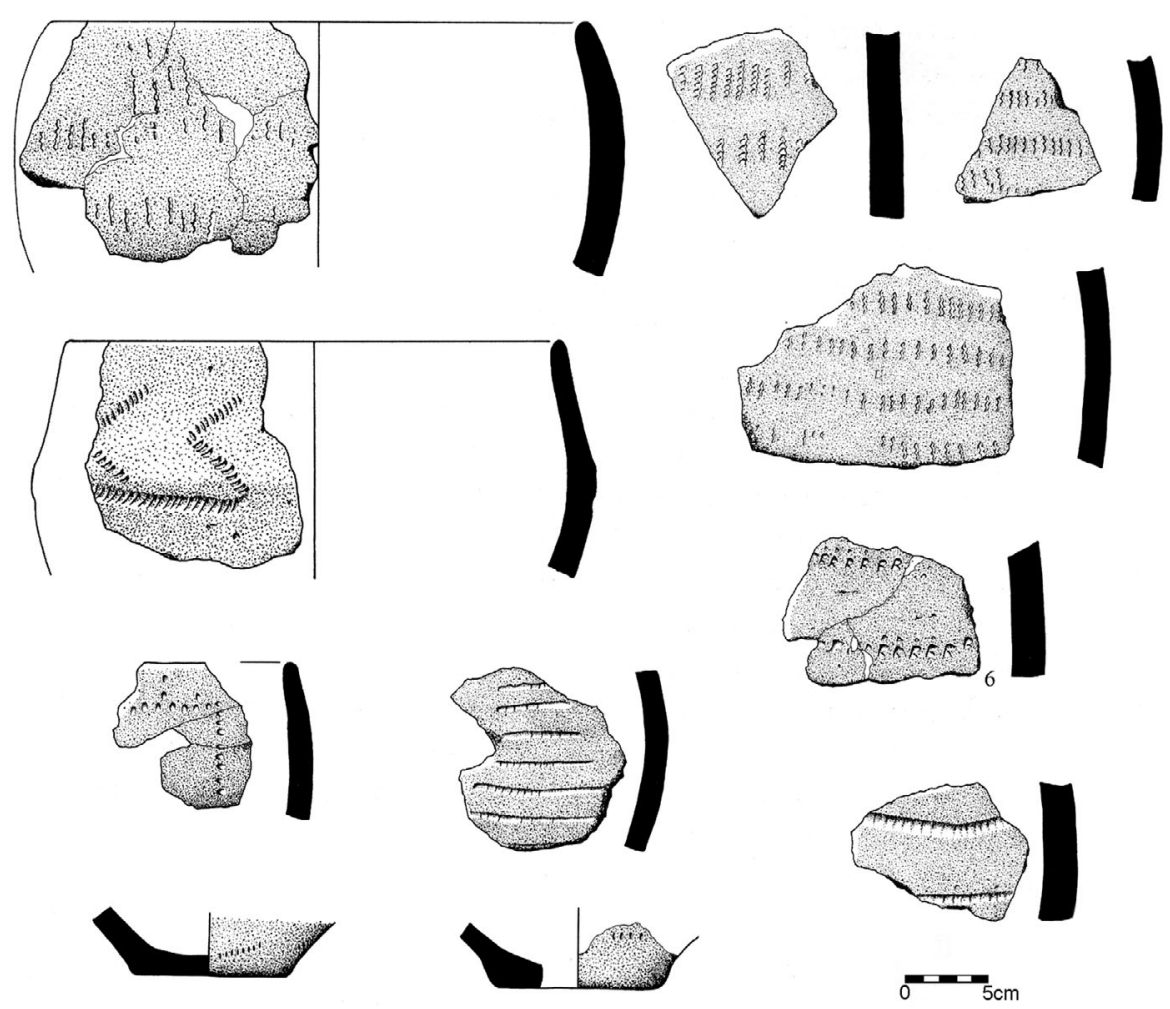

Fig. 3. Elementos cerámicos de Pont de Roque-Haute (Guilaine y Manen 2002: 41). 
El abrigo de Pendimoun (Castellar, Alpes-Maritimes) ofrece en su nivel III-base (Pendimoun 1) una ocupación que también debe ser relacionada con una presencia pionera previa al horizonte cardial clásico y que cronológicamente se situaría entre 5800 y 5600 cal BC (Binder et al. 1993; Binder y Maggi 2001). El registro arqueológico de esta fase de ocupación se caracteriza por una fuerte proporción de cerámica bruñida no decorada, dominando los vasos con fondo plano y asas verticales o lengüetas no perforadas. Los fragmentos decorados presentan bandas impresas con la uña o instrumento (pinzas), bandas impresas en zigzag o chevrons con concha de Cardium e impresiones pivotantes por toda la superficie. Este tipo de sintaxis decorativa remite, según Binder y Maggi (2001: 416), a conjuntos cerámicos de la Puglia, la Marche y los Abruzzos, pudiendo asociarse algunos elementos con la región de Calabria (Favella della Corte) y la isla de Giglio. En cuanto al registro lítico tallado, este nivel se caracteriza por la presencia de varios geométricos triangulares, uno con retoque abrupto diseñando truncaduras cóncavas y tres con retoque bifacial prácticamente plano, y de varias láminas con pátina de siega. Las bases económicas reflejan una amplia diversidad: predominio de la ganadería, principalmente basada en la cría de pequeños rumiantes, desarrollo de actividades agrícolas, constatadas a través de semillas, principalmente Triticum dicoccum y cebada, y leguminosas y tareas de recolección de moluscos con predominio de la familia de los patélidos (Binder et al. 1993; Binder y Maggi 2001). Estos datos inciden en la existencia de un grupo con economía de producción, pero dependiente también de los recursos de la naturaleza, que ocuparía el asentamiento de forma esporádica y cíclica según se desprende de la sucesión de estructuras de combustión documentadas en este primer horizonte neolítico. Con posterioridad, se observa una sucesión de niveles vinculados con un empleo funerario y con una ocupación especializada relacionada con la estabulación de ganado, ambos momentos insertos ya dentro de la tradición cardial tirrénico (Fig. 4).

Así, en torno al 5800-5400 cal BC existen diferentes estilos cerámicos contemporáneos en la costa del Languedoc y en el arco ligur-provenzal que pueden interpretarse como propios de diferentes facies culturales aunque con un origen itálico común. Pero estas similitudes no sólo quedan registradas en los elementos cerámicos sino que afectan a otras facetas del complejo socioeconómico de estas comunidades pioneras. A nivel económico, Peiro Signado y Pont de Roque-Haute
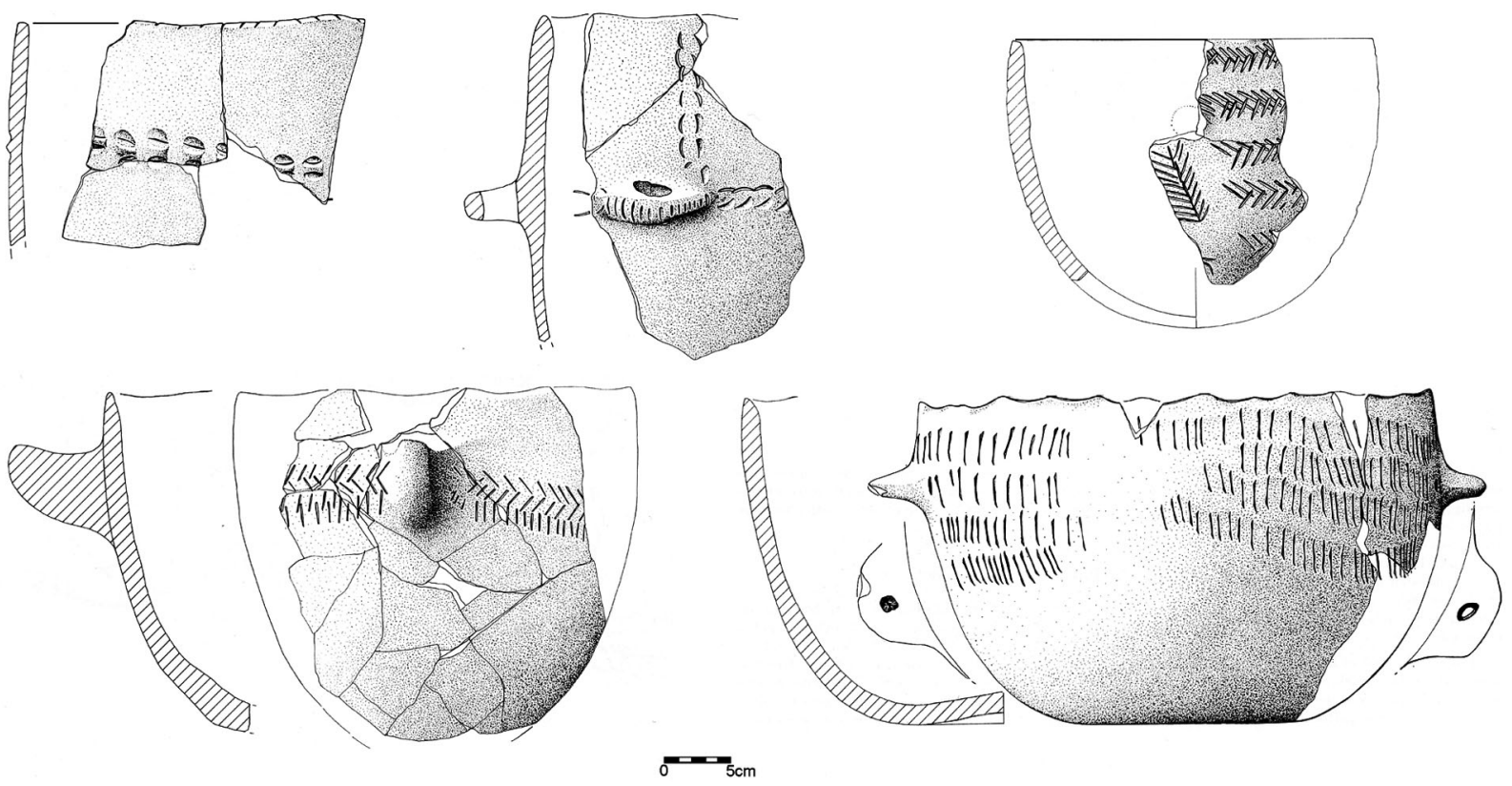

Fig. 4. Cerámica impresa de Pendimoun 1 (Binder et al. 1993).

T. P., 67, N. ${ }^{\circ}$ 1, enero-junio 2010, pp. 37-58, ISSN: 0082-5638 doi: $10.3989 /$ tp.2010.10030 
presentan una economía plenamente neolítica con un claro predominio de animales domésticos, principalmente ovicápridos, recursos vegetales cultivados, con especial incidencia del Triticum diccocum, recolección de conchas marinas, etc. Por otro lado, la industria lítica de ambos yacimientos repite algunos convencionalismos como la presencia mayoritaria de soportes laminares regulares con talón facetado, algunos retocados y otros empleados en la elaboración de trapecios simétricos, o el empleo de obsidiana que remite a contactos con el Tirreno.

Cabe remarcar que durante la facies sillon d'impressions, y también en el resto de facies analizadas, los asentamientos tienden a localizarse próximos a la costa, tanto los situados al aire libre como en el interior de cavidades. Esta distribución ha permitido plantear una colonización costera mediante cabotaje, hecho que explicaría la separación geográfica entre estos primeros asentamientos neolíticos (Binder y Maggi 2001: 421). Para J. Guilaine y C. Manen (2002), estas presencias puntuales en la zona costera mediterránea cabría relacionarlas con incursiones ocasionales por vía marítima que permiten inferir una serie de implantaciones pioneras en torno a 5750-5500 cal BC, momento de máximo desarrollo de la facies de ceramica impressa del sur de Italia (facies Guadone). Esta afirmación la sustentan en el hecho de que las estructuras documentadas y el registro arqueológico no permiten inferir una ocupación duradera, sino más bien períodos aislados de ocupación como ocurre en el yacimiento de Peiro Signado, que presenta un conjunto de fosas aisladas, o el horizonte inferior de Pendimoun, que se caracteriza por un episodio aislado de ocupación sin solución de continuidad con respecto al horizonte cardial posterior.

Estos yacimientos costeros con elementos propios de Italia meridional han sido asociados por M.A. Fugazzola (2002: 98) a navegaciones exploratorias o a puntos de apoyo o breve parada en el recorrido de estos grupos hacia Cerdeña, las costas tirrénicas de Italia central y las costas del Mediterráneo noroccidental, posibilidad que podría quedar reflejada por la presencia de elementos cerámicos propios de Italia meridional en el archipiélago toscano: Giglio, Coltano, La Scola o Cala Giovanna Piano (Pessina y Tiné 2008: 53). El desplazamiento a nuevos territorios no implicaría, en un principio, modificaciones sustanciales en el sistema cultural propio del lugar o luga- res de origen, cuestión que permite rastrear conexiones entre los distintos ámbitos del Mediterráneo occidental.

Las motivaciones de estos movimientos resultan complejas de establecer, aunque un elemento que destaca dentro de esta dispersión, y que ha sido recalcado para la expansión neolítica en la Europa central (Bogucki 2003), es el alto nivel de conservadurismo, que en el caso del Mediterráneo occidental queda reflejado en los patrones decorativos cerámicos y los modelos de ocupación y gestión económica del territorio. P. Bogucki (2003) y B. Martí (2008) se han cuestionado, para el ámbito centro-europeo y mediterráneo, respectivamente, sobre los estímulos de estos movimientos, apuntando la hipótesis de que estarían determinados por las decisiones de las unidades básicas de producción y organización social de los asentamientos de este momento, las familias, que tienen en los espacios de hábitat su mejor representación: las grandes casas alargadas del ámbito centroeuropeo, los compounds de Italia meridional, etc. De esta forma, las decisiones adoptadas en el seno de estos grupos familiares deberían estar también detrás de los desplazamientos de las áreas de residencia sin que estos deban estar explicados obligatoriamente por causas ecológicas o sociales. La importancia de las decisiones familiares en los desplazamientos explicaría el mantenimiento de las tradiciones de los lugares de origen como forma de reivindicar la pertenencia a un grupo social más amplio y la escasa entidad de los yacimientos pioneros cuyas características estratigráficas se relacionan más con ocupaciones plurifuncionales asociadas a pequeños grupos que con un uso dentro de estrategias de gestión del territorio totalmente consolidadas.

\section{3. "COLONOS NEOLÍTICOS": LAS EVIDENCIAS MÁS ANTIGUAS DE LA NEOLITIZACIÓN EN LAS COMARCAS CENTROMERIDIONALES VALENCIANAS}

El proceso de neolitización en las tierras valencianas se inicia, según las dataciones disponibles sobre muestras de vida corta, en torno al 5600 cal BC, momento en el que se asiste a la ocupación de cavidades, situadas tanto en la primera línea de costa (Cendres, Ampla, etc.) como 
en los valles interiores (Or, Sarsa, etc.), y de hábitats al aire libre (El Barranquet, Mas d'Is, etc.). Desde un principio se ocupan tanto la depresión prelitoral como las sierras y valles adyacentes, cubriéndose prácticamente todo el territorio de las actuales comarcas centromeridionales valencianas, proceso que podría equipararse a la fase pionera documentada en la región catalana (Mestres 1992: 74). Sin embargo, esta neolitización inicial no puede ni debe vincularse a un fenómeno de colonización estructurada asociada a movimientos de contingentes poblacionales amplios sino que, según trataremos de mostrar en las siguientes líneas, debió ser un fenómeno puntual, concreto $\mathrm{y}$, posiblemente, esporádico similar al descrito en los epígrafes anteriores.

A modo de hipótesis, los niveles iniciales de las secuencias neolíticas de asentamientos como Cendres o El Barranquet, y también otros yacimientos costeros sin estratigrafía o con unos registros escasos, bien podrían ser el reflejo de esta primera ocupación pionera de comunidades llegadas desde el Mediterráneo centro-occidental, suposición que queda insinuada a partir de las similitudes entre estas dos regiones por lo que respecta al registro material y económico.

La ocupación inicial del asentamiento costero de El Barranquet de Oliva (La Safor, Valencia), determinada a partir de la UE 79, presenta un conjunto arqueológico caracterizado por la presencia de elementos que podrían compararse con la situación descrita anteriormente para el Languedoc y el arco ligur-provenzal. El registro cerámico de esta unidad se define por un reducido número de fragmentos entre los que la técnica cardial está poco representada frente a otros tipos como cerámicas acanaladas, impresas de instrumento y la técnica de secuencia de impresiones (Esquembre et al. 2008: Fig. 4), características que podrían relacionarse con las observadas en la facies sillon d'impressions. Aunque aún preliminares, los datos económicos de El Barranquet inciden en la importancia de la recolección de moluscos con finalidad bramatológica durante los primeros momentos de ocupación neolítica, aunque la presencia de domésticos presenta también una fuerte incidencia. La datación obtenida sobre una muestra de Ovis aries, Beta-221431: $6510 \pm 50 \mathrm{BP}(5560 / 5360$ cal BC $2 \sigma)$ (Esquembre et al. 2008), unida a las características del registro cerámico, permite acercar la ocupación inicial del yacimiento de Oliva a la observada en contextos neolíticos antiguos del noroeste mediterráneo, aunque con las oportunas reservas impuestas por la provisionalidad de los datos publicados (Fig. 5).
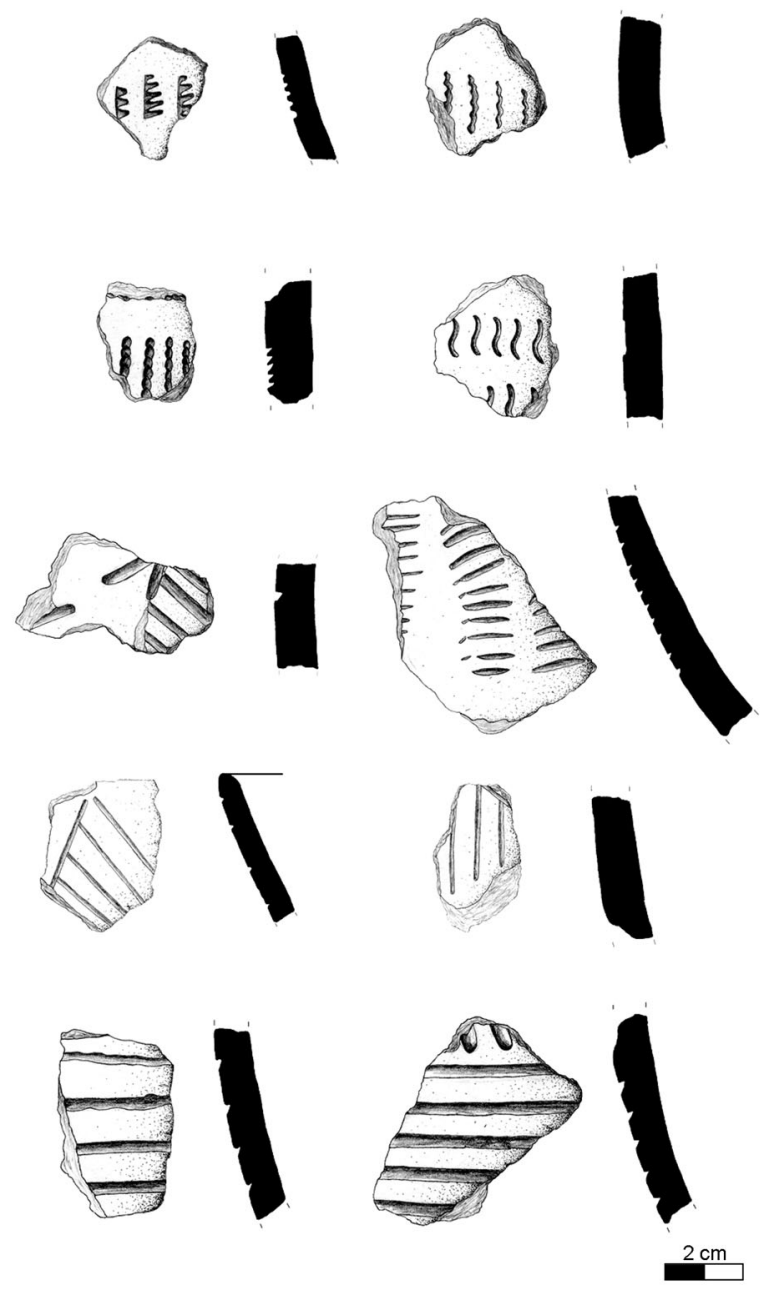

Fig. 5. Cerámica de la UE 79 de El Barranquet (Esquembre et al. 2008: 186).

Los primeros horizontes neolíticos de la Cova de les Cendres (Teulada-Moraira, La Marina Alta, Alicante) (niveles XI, X y IX del sector A) muestran, al igual que Barranquet, una explotación intensiva de los recursos del mar: la pesca, que posiblemente se procesaría en el mismo yacimiento, y el marisqueo, representado por acumulaciones de restos de alimentación formados por lapas (Patella sp.) y peonzas (Monodonta turbinata) (Llobregat et al. 1981: 100). Esta ocupación queda definida estratigráficamente por la 
existencia de un grupo de fosas excavadas que pueden interpretarse como silos de almacenamiento, algunos de los cuales conservaban en su interior vasos aptos para tal fin (Bernabeu et al. 2001: 70). Estos indicios apuntan hacia una frecuentación de marcado carácter funcional que, sin descartar tampoco el uso habitacional, indicaría un uso en épocas del año prolongadas vinculado con una gestión amplia y diversificada de los recursos económicos del territorio circundante. En relación con esta posibilidad estarían los datos apuntados por los análisis paleoambientales que denotan para este momento una cierta degradación del entorno del yacimiento (Badal et al. 1991: 47; Bernabeu et al. 2001: 63) que puede asociarse con la práctica de abrir campos con fuego para desarrollar en las proximidades de la cavidad una economía de carácter agropastoril. Resulta imposible definir en qué momento del año se llevarían a cabo estas actividades o si éstas se realizaban de manera continuada. En este sentido, la ausencia de muchos de los elementos esqueléticos del pescado capturado impide cualquier aproximación, a lo que cabe añadir que las especies predominantes en los niveles iniciales del Neolítico (mero, pagro y dorada) son de carácter costero y en la actualidad se capturan durante todo el año. Además de ésta, quedan pendientes otras muchas cuestiones en torno a esta primera ocupación de la cavidad de la Punta de Moraira, aunque parece evidente que existió una organización interna en la que la zona interior se emplearía como lugar de almacenamiento y hábitat asociado a la explotación de los recursos marinos, principalmente los malacológicos. Con estas primeras evidencias neolíticas de Cendres cabe relacionar varios fragmentos con decoración pintada (Bernabeu 1995: 40), técnica escasamente documentada en los horizontes cardiales clásicos y más propia de contextos impresos del sur de Italia (Tiné 2002).

Para la Cova Ampla del Montgó (Xàbia, La Marina Alta, Alicante), yacimiento sin estratigrafía definida y del cual procede un extraordinario conjunto material (Esquembre y Torregrosa 2007), se ha planteado (Soler 2007: 38) su relación con contextos impresos del centro de Italia a partir de algunos fragmentos cerámicos con modelos decorativos que recuerdan al cardial tirrénico (también llamado linee dentellate o estilo BPF -Basi-Pienza-Filiestru-), estilo característico de la banda costera italiana situada entre las cuencas del Arno y el Tíber y las islas del archipiélago toscano. En este sentido, la presencia de decoraciones a base de impresiones en sentido vertical mediante el empleo de una concha con borde dentado (principalmente Cardium) remitirían a la ceramica impressa evolucionada (Tiné, 2002), aunque su presencia se observa también en otros contextos impresos del Mediterráneo occidental (Fig. 6).
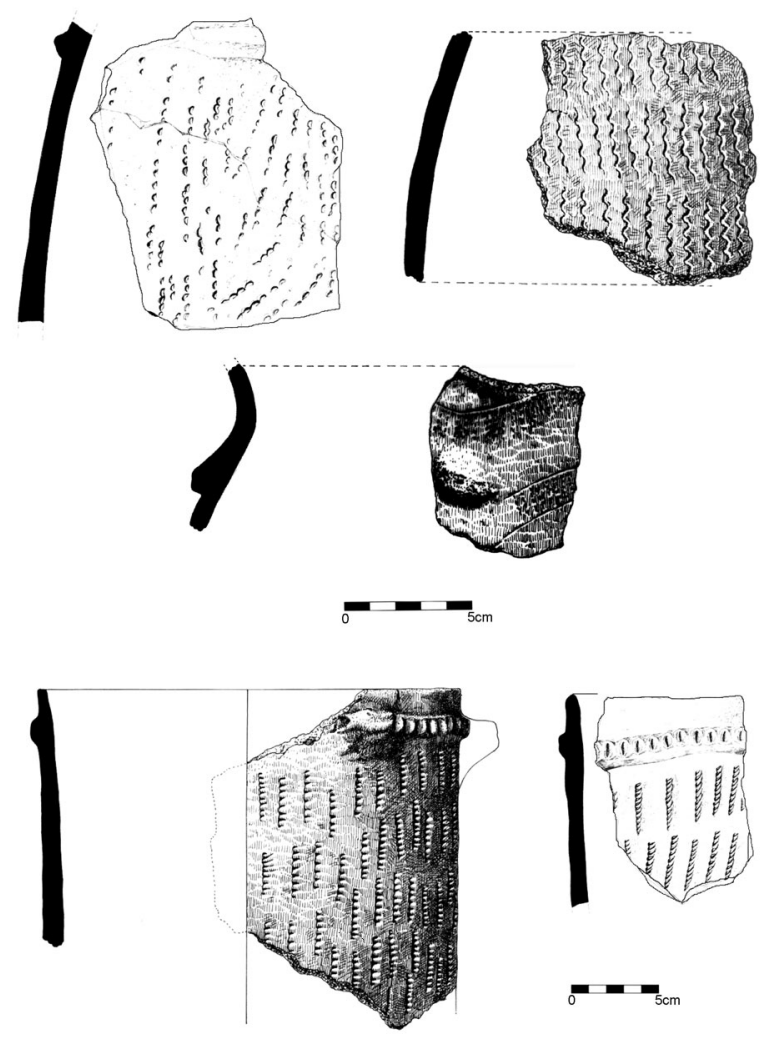

Fig. 6. Cerámicas impresas de la Cova Ampla del Montgó asimilables al ámbito tirrénico (Soler 2007: 65, 67, 69).

El análisis del registro paleoeconómico de estos asentamientos costeros, tanto en el sector rocoso entre las desembocaduras de los ríos Girona y Algar como en torno a la llanura de Marxuquera y la desembocadura del Serpis, muestra un sistema basado en la explotación de una amplia variabilidad de recursos centrados, básicamente, en una cabaña ganadera compuesta principalmente por ovicaprinos y en el aprovechamiento de recursos malacológicos. Esta forma de gestión resulta similar al observado en los primeros niveles 
neolíticos de las cavidades ligures de Arene Candide o Grotta Pollera o de los asentamientos al aire libre de Pont de Roque-Haute o Peiro Signado.

No obstante, el marco radiocarbónico actual no limita la presencia pionera al sector costero, sino que también se observa de manera temprana en los valles interiores, pudiendo tratarse de ocupaciones simultáneas o inmediatamente posteriores a las realizadas en el primer momento de ocupación neolítica de este punto de la costa mediterránea de la Península Ibérica. Se observa que la elección de los yacimientos en los valles interiores responde a una preocupación por controlar aquellos recursos que habían de ser explotados con mayor asiduidad por una comunidad con economía de producción básica, eligiendo siempre las mejores tierras para ubicar los asentamientos de hábitat estable, modelo de ocupación que encuentra su mejor reflejo en el paraje de Les Puntes (Benifallim-Benilloba-Penàguila, L'Alcoià-El Comtat, Alicante) (Bernabeu et al. 2002; Bernabeu et al. 2003). En este momento de ocupación pionera, en el centro de esta antigua cuenca semiendorreica se documentan una serie de cabañas diseminadas que no presentan una delimitación física palpable, localizaciones que podrían corresponderse con estructuras de habitación que albergarían a unidades familiares con cierto grado de autosuficiencia (granjas), afirmación que vendría apoyada por su asociación con pequeñas estructuras de carácter doméstico (fosas, hogares, molinos, etc.). Esta independencia también se puede inferir a partir de las características tecnológicas de la cerámica que apuntan, según análisis de fragmentos cerámicos de la Casa 1 (sector 52; Beta-166727: $6600 \pm 50 \mathrm{BP}$; 5620/5481 cal BC $2 \sigma$ ) y Casa 2 (sector 80; Beta-162092: $6600 \pm$ $50 \mathrm{BP} ; 5620 / 5481$ cal BC $2 \sigma$ ) del Mas d'Is, hacia producciones totalmente independientes que podrían relacionarse con un sistema de transmisión tecnológica en sentido vertical entre generaciones (McClure 2007: 500). Por otro lado, el yacimiento de Mas d'Is también ha sido vinculado con contextos pioneros a través de la presencia de unos pocos fragmentos de cerámica decorada con la técnica sillon d'impressions (Bernabeu et al. 2009) que aparecen junto a cerámica propia del horizonte cardial en algunas de las estructuras más antiguas (Casa 1 y Foso 5).

A estas evidencias se puede unir el nivel VIII inferior de la Cova d'En Pardo (Planes, El Com- tat, Alicante), nivel de ocupación cuya base se caracteriza por la existencia de un hogar en cubeta vinculado a restos derivados de actividades cinegéticas (Soler et al. e.p.). En este mismo contexto se determinó la presencia de un recipiente cerámico, Vaso 7, con una decoración a base de impresiones de instrumento de punta simple a modo de corchetes que puede relacionarse con distintos ámbitos mediterráneos, principalmente el ligur donde se han registrado motivos de idéntica técnica y sintaxis en yacimientos como Arene Candide (Tiné 1974; Traverso 2002) o Grotta Pollera (Odietti 1974, 2002). Las características de este conjunto arqueológico permiten inferir la existencia de un contexto momento vinculado a una presencia de carácter esporádica y puntual que cronológicamente hay que situar en los últimos momentos de la primera mitad del VI milenio cal BC. A esta ocupación le superpone otra -nivel VIII-, separadas por apenas 50 años del nivel infrayacente que, a partir de su registro cerámico, debe ser caracterizada como plenamente cardial (Soler et al. e.p.).

Lo breve de estas ocupaciones y el hecho de que se hayan determinado cerámicas asimilables a conjuntos arqueológicos propios del Neolitico impresso del arco noroccidental mediterráneo obliga a retener la posibilidad de que estos horizontes arqueológicos estén unidos al proceso de colonización inicial de las comarcas valencianas. Este fenómeno bien podría rastrearse en otros yacimientos como la Cova de la Sarsa (Bocairent, la Vall d'Albaida, Valencia) donde se han evidenciado fragmentos cerámicos -sin contexto arqueológico- que podrían asociarse a la facies sillon d'impressions (Cortell y García 2007: 68) (Tab. 1).

La situación reflejada por los yacimientos mencionados anteriormente, además de otros asentamientos que requerirán de su correspondiente revisión, habla de comunidades neolíticas llegadas desde uno o varios puntos de la vertiente noroccidental mediterránea, muy posiblemente desde el arco ligur-provenzal o el Languedoc si nos atenemos a las características de sus conjuntos cerámicos, que se asientan en torno a las desembocaduras de los ríos Xaló, Girona y Serpis y que, durante los primeros momentos de ocupación pionera, desarrollan una serie de prácticas económicas tendentes a minimizar los riesgos propios de las economías agropastoriles primitivas mediante la recolección intensiva de moluscos o la caza. Este hecho y las característi- 


\begin{tabular}{|c|c|c|c|c|c|c|c|}
\hline YAC. & CONTEXTO & MUESTRA & REF. LAB. & BP & cal BC $1 \sigma$ & cal BC $2 \sigma$ & FUENTE \\
\hline En Pardo & Nivel VIII inf & $\begin{array}{c}\text { Capra } \\
\text { pyrenaica }\end{array}$ & Beta-231880 & $6660 \pm 40$ & $5619-5545$ & $5631-5509$ & Soler et al. e.p. \\
\hline En Pardo & Nivel VIII & $\begin{array}{l}\text { Ovis/ } \\
\text { Capra }\end{array}$ & Beta-231879 & $6610 \pm 40$ & $\begin{array}{l}5614-5587 \\
5568-5514\end{array}$ & $5619-5487$ & Soler et al. e.p. \\
\hline Mas d'Is & $\begin{array}{c}\text { Ue80205. } \\
\text { Fase VIb. } \\
\text { Casa } 2\end{array}$ & $\begin{array}{l}\text { Hordeum } \\
\text { vulgare }\end{array}$ & Beta-166727 & $6600 \pm 50$ & $\begin{array}{l}5610-5592 \\
5563-5509 \\
5500-5491\end{array}$ & $5617-5484$ & Bernabeu et al. 2003 \\
\hline Mas d'Is & $\begin{array}{c}\text { Ue80219. } \\
\text { Fase VIa. } \\
\text { Casa } 1\end{array}$ & $\begin{array}{l}\text { Hordeum } \\
\text { vulgare }\end{array}$ & Beta-162092 & $6600 \pm 50$ & $\begin{array}{l}5610-5592 \\
5563-5509 \\
5500-5491\end{array}$ & $5617-5484$ & Bernabeu et al. 2003 \\
\hline El Barranquet & UE 79 & $\begin{array}{l}\text { Ovis } \\
\text { aries }\end{array}$ & Beta-221431 & $6510 \pm 50$ & $\begin{array}{l}5527-5467 \\
5444-5386\end{array}$ & $5584-5373$ & Esquembre et al. 2008 \\
\hline Falguera & UE2051B & $\begin{array}{c}\text { Triticum } \\
\text { monococum }\end{array}$ & Beta-142289 & $6510 \pm 70$ & $\begin{array}{l}5536-5463 \\
5449-5378\end{array}$ & $\begin{array}{l}5614-5587 \\
5568-5328\end{array}$ & Bernabeu et al. 2001 \\
\hline Or & $\begin{array}{c}\text { CapaVII/ } \\
\text { Inferior/H3 }\end{array}$ & $\begin{array}{c}\text { Triticum } \\
\text { monococum }\end{array}$ & $\mathrm{KN}-51$ & $6510 \pm 160$ & $\begin{array}{l}5616-5584 \\
5572-5325\end{array}$ & $\begin{array}{l}5732-5205 \\
5168-5076\end{array}$ & Martí 1978 \\
\hline Cendres & H16 & $\begin{array}{l}\text { Triticum } \\
\text { dicocum }\end{array}$ & Gif-10136 & $6490 \pm 90$ & $5531-5366$ & $5617-5310$ & Bernabeu et al. 2001 \\
\hline Cendres & E VII & $\begin{array}{l}\text { Hordeum } \\
\text { vulgare }\end{array}$ & Beta-142228 & $6340 \pm 70$ & $\begin{array}{l}5462-5450 \\
5376-5282 \\
5276-5224\end{array}$ & $5478-5207$ & Bernabeu et al. 2001 \\
\hline Or & $\begin{array}{c}\text { J4/ } \\
\text { Capa 17a }\end{array}$ & Cereal & Oxa-10192 & $6310 \pm 70$ & $5366-5221$ & $\begin{array}{l}5470-5205 \\
5168-5076\end{array}$ & Zilhão 2001 \\
\hline Cendres & E VIIa & $\begin{array}{l}\text { Ovis } \\
\text { aries }\end{array}$ & Beta-107405 & $6280 \pm 80$ & $\begin{array}{l}5361-5207 \\
5161-5137 \\
5129-5120 \\
5095-5080\end{array}$ & $\begin{array}{l}5467-5403 \\
5387-5047\end{array}$ & Bernabeu et al. 2001 \\
\hline Or & $\begin{array}{c}\text { J4/ } \\
\text { Capa } 14\end{array}$ & $\begin{array}{c}\text { Triticum } \\
\text { monococum }\end{array}$ & Oxa-10191 & $6275 \pm 70$ & $\begin{array}{l}5328-5207 \\
5162-5137 \\
5130-5120 \\
5104-5080\end{array}$ & $\begin{array}{l}5465-5443 \\
5423-5407 \\
5381-5047\end{array}$ & Zilhão 2001 \\
\hline
\end{tabular}

Tab. 1. Dataciones sobre muestras de vida corta de contextos asociados a la primera implantación neolítica en tierras valencianas. OxCal v4.1.3; Bronk Ramsey (2009).

cas arqueológicas de los conjuntos asociados a esta primera implantación nos estarían indicando, además, un peso demográfico reducido articulado en torno a unidades productivas de carácter familiar.

Tras unas pocas generaciones, estas comunidades pioneras se ampliarían demográfica y territorialmente según muestra la presencia de elementos típicamente cardiales en los distintos valles prelitorales de las comarcas centromeridionales valencianas. Buen reflejo de este proceso de estabilización del sistema socioeconómico sería la aparición del Foso 5 de Mas d'Is, cuya colmatación se inicia $c a$. 5480/5310 (Beta-171906: $6400 \pm 40$ BP). La enorme movilización de mano de obra destinada a la construcción de los fosos monumentales de Mas d'Is, interpretada como un fenómeno puntual de jerarquización social (Bernabeu et al. 2006), permite inferir la estabilización de los patrones de ocupación y la aparición de rituales de agregación intratribales del grupo local asentado de manera dispersa en la cuenca del Riu Penàguila (Bernabeu et al. 2003; Bernabeu et al. 2006). Otro elemento que permite observar la consolidación social de los grupos neolíticos en el ámbito de las comarcas septentrionales alicantinas sería la aparición del arte rupestre macroesquemático, que tiene precisamente en la cerámica impresa cardial sus mejores paralelos muebles (Martí y Hernández 1988). Esta 
manifestación ha sido explicada como el reflejo de prácticas sociales de agregación intertribal (Hernández 2000), posiblemente relacionadas con los distintos grupos que en este momento ocupan el denominado territorio cardial. (Fig. 7).

\section{EL COMPLEJO CARDIAL ZONADO Y LA CONSOLIDACIÓN TERRITORIAL DEL MODO DE VIDA NEOLÍTICO}

A nivel estilístico, la facies cardial franco-ibérica o cardial zonado se caracteriza por la presencia de motivos repetidos de manera sistemática realizados mediante impresiones cortas con el borde de la concha de Cardium dispuestas en bandas horizontales delimitadas o zonadas y rellenas de impresiones verticales u horizontales, chevrons o zigzag. Las decoraciones plásticas es- tán representadas por cordones ortogonales lisos, cordones horizontales digitados, ungulados o con impresión cardial. Otro tipo de decoraciones son las impresiones irregulares dispuestas en filas horizontales, impresiones de uña, digitaciones o pinzamientos sobre la parte superior del vaso. A nivel formal encontramos una amplia variedad: vasos esféricos, vasos semiesféricos y troncocónicos, botellas, micro-vasos, tapaderas, cucharas y vasos con pipa. Se documentan también fondos convexos o con cordón formando base anular, siendo escasas las bases planas, más propias de la ceramica impressa de Italia meridional, o la decoración tipo rocker no dentado, propia del ámbito adriático y de las distintas facies itálicas de la región noroccidental mediterránea. No obstante, y a pesar de la aparente uniformidad, se observan algunas diferencias internas dentro del marco de expansión del horizonte cardial (Manen 2002;

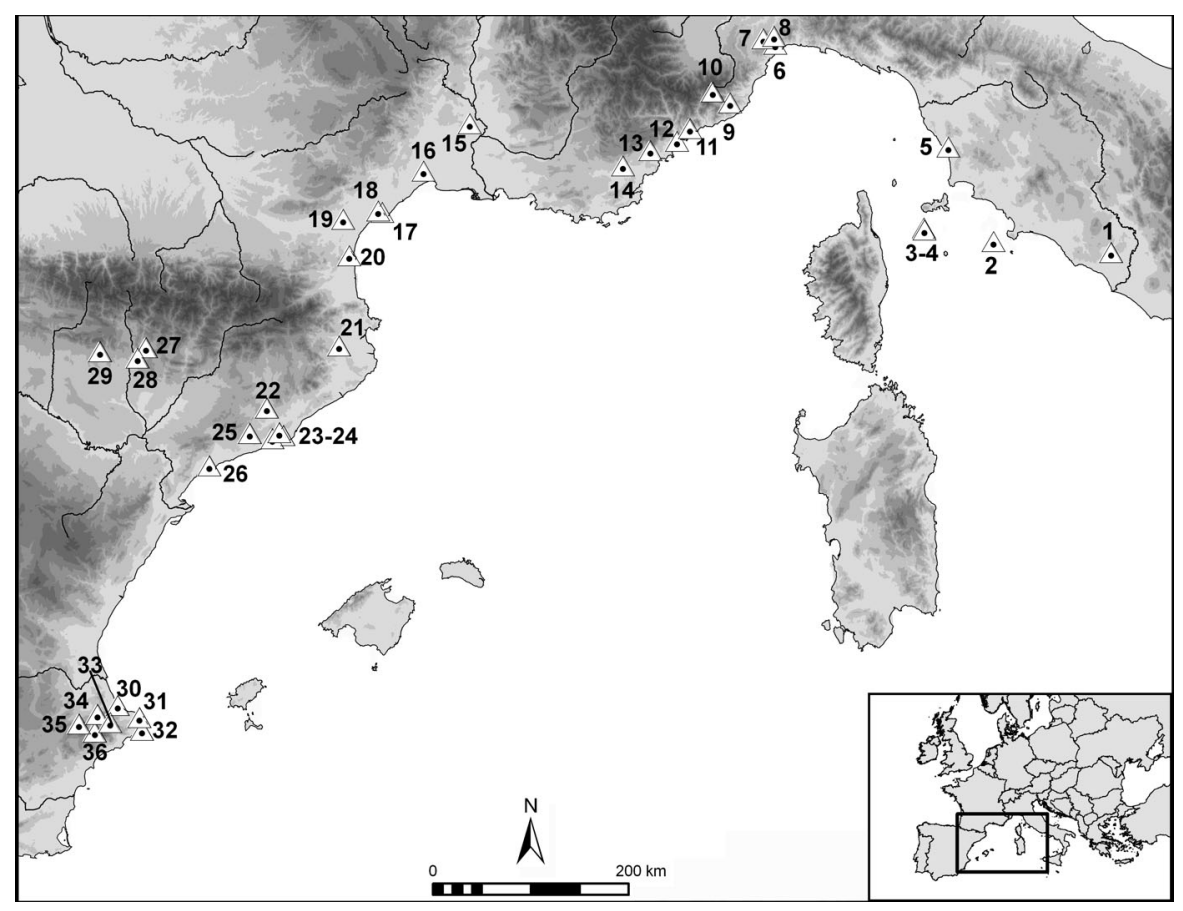

Fig. 7. Localización de los principales yacimientos mencionados en el texto. 1: La Marmotta; 2: Le Secche; 3: La Scola; 4: Cala Giovanna Piano; 5: Coltano; 6: Arene Candide; 7: Grotta Pollera; 8: Arma di Nasino; 9: Pendimoun; 10: Grotte Eole; 11: Station du magasin de Giaume; 12: Caucade; 13: Station Sans-Peur; 14: Sainte-Catherine; 15: Codòyeres; 16: Etang de Launac; 17: Pont de Roque-Haute; 18: Peiro Signado; 19: Grotte de Bize; 20: Grotte des Fées; 21: La Draga; 22: Coves de Montserrat; 23: Caserna de Sant Pau; 24: Cova de Can Sadurní; 25: Guixeres de Vilobí; 26: El Cavet; 27: Abrigo de Forcas II; 28: Cueva del Moro de Olvena; 29: Cueva de Chaves; 30: El Barranquet; 31: Cova Ampla del Montgó; 32: Cova de les Cendres; 33: Cova d'En Pardo; 34: Cova de l'Or; 35: Cova de la Sarsa; 36: Mas d'Is. 
Willigen 2004) que podrían explicarse por los mecanismos de formación y expansión de cada uno de estos grupos tras el proceso de asentamiento pionero.

El proceso de implantación cardial, que podría equipararse a la fase neopionera de A. Gallay (1989), es mucho más generalizado y complejo que el de las ocupaciones pioneras observadas anteriormente pues se observa una importante presencia en los valles interiores y una mayor estructuración en el sistema económico. Cabría plantearse si este desarrollo del horizonte cardial estaría relacionado con el proceso de difusión/consolidación y con los cambios socioculturales operados tras la plena implantación de los grupos colonizadores. Asociado a esta idea estaría el hecho de que el complejo cardial presenta un sistema socioeconómico mejor integrado a la diversidad ambiental, elemento que tiene su mejor reflejo en la amplia variedad de soluciones económicas. Esto se traduce en la existencia de un sistema de gestión del territorio que, a grandes rasgos, es similar dentro del ámbito cardial (Guilaine 1986; Binder 2000; García 2009). La aparición de asentamientos al aire libre junto a terrazas fluviales (Le Baratin, Escanin, Petites Batîes, Apt, Plansallosa, Mas d'Is, etc.) y zonas endorreicas (Leucate, La Draga, etc.) es otra de las tónicas que se repite sistemáticamente. El registro estructural y material de los yacimientos cardiales en llano denota una fuerte estabilización de las zonas de hábitat por lo que cabría considerar a estos enclaves como zonas de hábitat continuado. Por otro lado, en el área provenzal y, sobre todo, en la región franco-ibérica, algunas cavidades juegan un papel importante en la gestión del espacio, observándose ocupaciones especializadas en una o varias actividades (caza, pastoreo, etc.), aunque éstas tienden a situarse en la periferia de los territorios agrícolas. Así, la existencia de una compleja red de asentamientos a lo largo de las diferentes cuencas del área de implantación cardial refleja el éxito del modelo de ocupación y la consolidación socioeconómica de este horizonte. La repetición de este sistema a lo largo de las diferentes regiones, con cierta variabilidad impuesta por el entorno inmediato y la base social que lo desarrolla, originará una visión de conjunto similar en este territorio, aunque pronto se observará que cada zona evolucionará de manera independiente durante los llamados horizontes epicardiales.
De esta manera, la cultura cardial podría interpretarse como el resultado de un proceso de expansión estructurada en el seno de los territorios de implantación pionera y su aparición podría corresponderse con el fenómeno arrítmico planteado por J. Guilaine (2000). Como ocurriera en Italia sudoriental 800-700 años atrás, aparece ahora un nuevo conjunto sociocultural que guarda ciertas semejanzas con el grupo de la ceramica impressa, pero que, como se mostraba en las líneas anteriores, presenta una personalidad propia a varios niveles. Este hecho obliga a plantear varias cuestiones:

a) cuál fue el papel jugado por los asentamientos pioneros en el posterior desarrollo del conjunto cardial franco-ibérico.

b) si la formación del horizonte cardial (zonado y tirrénico) es el resultado de la adaptación de los grupos pioneros a nuevas condiciones medioambientales y sociales diferentes a las existentes en el lugar de origen.

c) si el desarrollo de la cerámica impresa cardial es producto de la trasformación de la ceramica impressa como superación de los cambios advertidos en el núcleo de origen que tienden hacia un mayor sinecismo poblacional en torno a grandes poblados delimitados por enormes fosos en espiral, cuestión que podría interpretarse como el reflejo de una incipiente jerarquización social.

Con independencia de la casuística que explique la aparición del horizonte cardial, es evidente que éste se constata en el territorio litoral del Mediterráneo occidental, aunque pronto se produce una rápida expansión hacia el ámbito interior a través de ejes fluviales: Ródano, Ebro, Llobregat, Serpis, etc.

Retomando la cuestión de su génesis, el cardial zonado presenta un fuerte parentesco con el cardial tirrénico por lo que respecta a la geometrización de los temas decorativos, la presencia de fondos planos en el horizonte cardial de las comarcas centreomeridionales valencianas y la proximidad morfológica y estilística entre los microvasos del cardial geométrico de Pendimoun y los de Sarsa y Or (Binder 1995: 60). No obstante, también existen puntos de separación a nivel de registro material, principalmente en los estilos cerámicos ya que, mientras en el ámbito franco-ibérico las decoraciones se disponen principalmente en bandas horizontales, delimitadas y rellenadas con impresiones cardiales, a las cuales se pueden añadir otros motivos (triángulos, guirnaldas, etc.) 
en perpendicular, en el ámbito tirrénico los motivos decorativos están constituidos por bandas, por lo general de tendencia oblícua, delimitadas con impresiones del borde de conchas dentadas y rellenadas de trazos igualmente dentados, oblicuos u horizontales, formando metopas, zigzags o triángulos (Binder 1995; Grifoni 2001). Por lo que respecta a la industria lítica tallada, advertíamos líneas atrás una cierta homogeneidad en las producciones de Peiro Signado y Pont de Roque-Haute (talones facetados, talla por presión, empleo de obsidiana), imagen que contrasta con los rasgos advertidos para el cardial zonado caracterizado por una preparación proximal de los soportes laminares basada en el tratamiento sistemático por abrasión de las cornisas, lo cual genera talones lisos, y por el empleo de la percusión indirecta como técnica de extracción (Binder 1987; Cava 2000; Briois 2005; García 2005).

Además del registro material, los rasgos económicos también permiten advertir semejanzas y divergencias entre las distintas regiones del occidente mediterráneo. Así, en el horizonte cardial zonado se observa cierta preferencia por el trigo y la cebada desnuda (Manrival 1999) frente al farro o ammidonier (Triticum dicoccum), especie característica de los primeros horizontes neolíticos de Italia y de los enclaves pioneros del arco ligur-provenzal. Por otro lado, la explotación animal del ámbito del cardial zonado, caracterizada por el importante papel de las cabras y la fuerte presencia de caza, se aproxima a lo existente en el horizonte impreso tirrénico donde se determina también una importancia relativa de las prácticas cinegéticas y porcentajes equilibrados entre bovinos y caprinos. Esta imagen de un sistema económico menos especializado contrasta con la ofrecida por el ámbito griego y el sureste de Italia caracterizada por el pastoreo de bovinos y la cría de cerdos (Vigne 1999). Estas discrepancias regionales pueden ser explicadas a partir de las diferentes condiciones medioambientales y geográficas entre las diversas regiones, pero también desde criterios sociales como los distintos objetivos de la producción alimenticia, las formas de organización del trabajo o la presencia de tradiciones locales.

Las diferencias observadas con respecto al cardial tirrénico dificultan considerar al cardial como un horizonte globalmente importado desde aquella región (Guilaine y Manen 2007: 42).
La opción de un desarrollo fruto de la evolución local de las poblaciones mesolíticas tras el contacto con los grupos de origen itálico, al menos en las zonas de implantación pionera, tampoco se sustenta una vez advertidas las notables diferencias en los registros líticos de los últimos cazadores-recolectores y las primeras comunidades neolíticas (Binder 1987; Juan-Cabanilles 1992; García 2005; Juan-Cabanilles y Martí 2007/2008).

De esta manera, las particularidades mostradas por el complejo cardial zonado obligan a considerar la posibilidad de una transición demográfica (Guilaine y Manen 2007: 42) en la que, tras la implantación de contingentes poblacionales de origen itálico en las costas del Mediterráneo noroccidental, su ampliación demográfica y la consolidación social de las mismas, se generaría una nueva realidad socio-cultural. Para explicar este fenómeno de reformulación cultural pueden considerarse diversas variables como la importancia jugada por el sustrato mesolítico en la recepción y posterior difusión hacia el Oeste de las innovaciones neolíticas, la existencia de varios focos de difusión cultural con diversos fenómenos de recomposición cultural, la relación con otras regiones mediterráneas como la tirrénica, con la cual comparte aspectos ya mencionados, o la presencia de desarrollos locales y autónomos en cada uno de los núcleos de asentamiento pionero.

\section{RECAPITULANDO: EL MODELO ARRÍTMICO DE LA NEOLITIZACIÓN}

Las evidencias mostradas anteriormente permiten recuperar y avalar la explicación ofrecida hace una década por J. Guilaine (2000) según la cual la propagación neolítica debió hacer frente a diferentes elementos en cada una de las regiones que se iban incorporando a este fenómeno. De esta manera, factores como el medio ambiente, la reacción de las poblaciones locales, el marco geográfico, etc. pudieron hacer variar el ritmo de la difusión. Para la neolitización del Mediterráneo, Guilaine (2000) propuso un modelo con frenazos y acelerones asociados a la superación de los límites impuestos por los condicionantes mencionados. Estos frenazos quedarían registrados arqueológicamente en aquellos lugares en los que se opera un cambio sustancial en el registro tec- 
nológico, económico e ideológico creándose zonas de frontera cultural (Fig. 8):

A. Anatolia: frontera occidental del PPNB

B. Norte de los Balcanes: génesis y desarrollo de la cerámica de bandas

C. Grecia oriental: génesis de la cultura adriática de la cerámica impresa

D. Portugal: frontera de la zona climática mediterránea y del cardial clásico

Uno de los exponentes de estas situaciones de recomposición cultural sería la existencia de diversas facies cerámicas en el arco noroccidental mediterráneo. El nuevo estilo cerámico, el cardial zonado, podría entenderse como un rasgo de identificación cultural que iría asociado a la superación de estas fronteras culturales aunque, como hemos visto en líneas anteriores, no es lo único que cambia ya que también se deja notar en otros elementos del registro tecno-económico y en los patrones de asentamiento. De esta forma, habría que entender la presencia en las tierras valencianas de elementos propios del ámbito ligur-provenzal como el reflejo del avance de la neolitización hacia estas tierras, expansión que tuvo un carácter pionero y puntual en tanto afectó de for- ma desigual y desestructurada a diversas regiones del litoral mediterráneo peninsular.

Este proceso de implantación pionera, reconocido ahora para las comarcas centromeridionales valencianas a partir de la UE 79 de El Barranquet y de elementos intrusivos dentro de conjuntos propiamente cardiales, también quedaría insinuado por cerámicas con decoración a base de secuencias de impresiones (definido también como boquique o punto y raya) en la Cueva del Moro de Olvena (Baldellou y Ramón 1995: 130) y en los niveles inferiores de la Cueva de Chaves (Ramón 2006). Pero estos elementos también se apuntan en el litoral catalán a partir del asentamiento de El Cavet (Cambrils, Tarragona) donde puede distinguirse, entre los materiales procedentes de las recogidas antiguas, algún fragmento decorado que podría haber sido realizado mediante la técnica sillon d'impressions (Oms y Morales 2008: 110, Lám. 1). No obstante, y al igual que ocurre en algunos de los contextos valencianos, su presencia en este último yacimiento resulta ínfima si se compara con el número de fragmentos con decoración impresa cardial, impresa de instrumento e impresa de concha no cardial. El

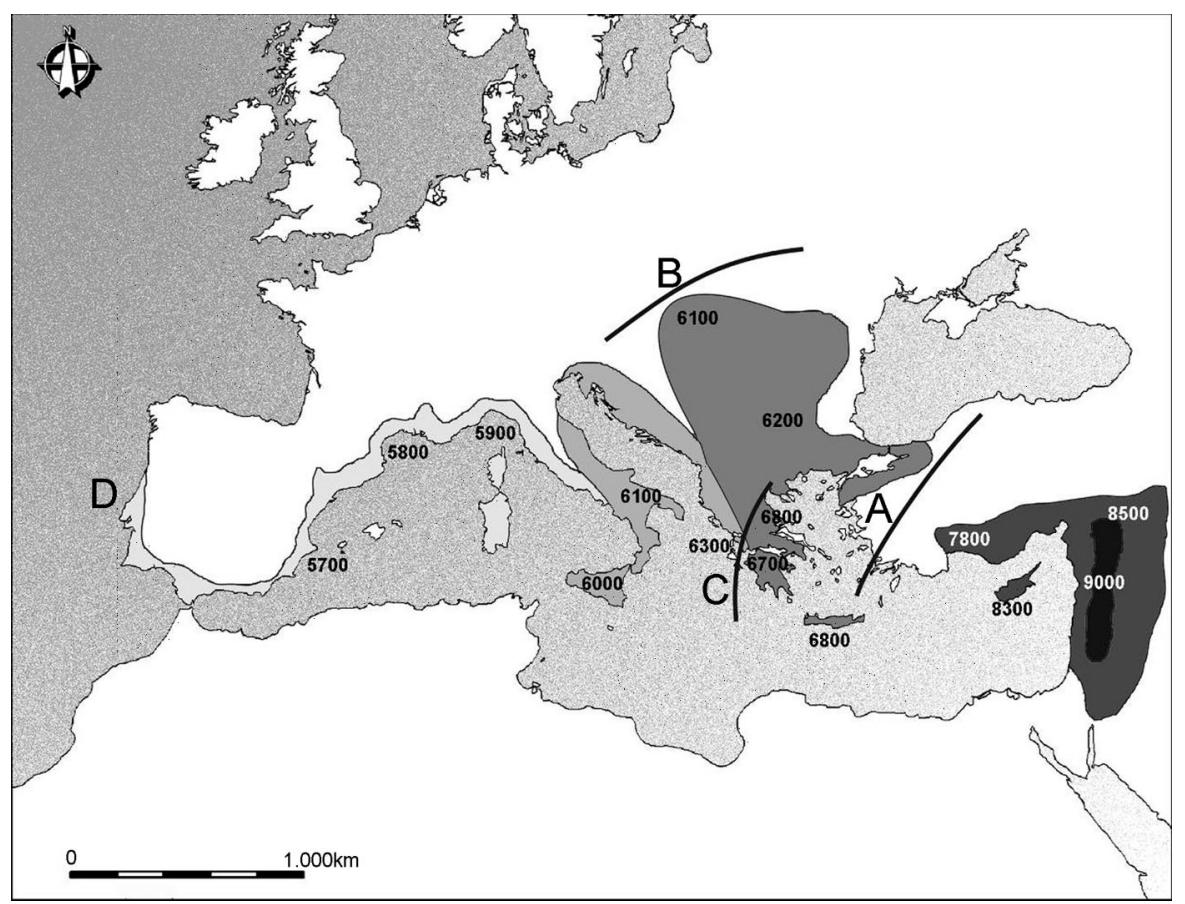

Fig. 8. Difusión cronológica del Neolítico por el Mediterráneo (a partir de Guilaine 2000: fig. 1). Fechas en expresión calibrada. 
registro cerámico permite situar la utilización de algunas de las fosas documentadas en los momentos iniciales del Neolítico antiguo, caracterización cronológica acorde con la fecha obtenida sobre una muestra de carbón (4) de Quercus sp. (Beta-222342 $6620 \pm 60 ; 5630-5470$ cal BC 2 $\sigma$ ) (Fontanals et al. 2008).

En relación con la posible existencia de diversas facies en el Neolítico inicial, cabe recuperar la idea planteada por diversos autores referida a la escasa incidencia del doble bisel en el geometrismo de los yacimientos del Neolítico inicial al sur del Turia (Juan-Cabanilles 1984; García 2005) y la mayor presencia de esta técnica en las tierras del noreste peninsular (Cava 2000; Juan-Cabanilles y Martí 2007/2008), diferencia que pudiera deberse a un distinto origen neolítico y/o a la interacción con grupos epipaleolíticos en la zona del Bajo Aragón. En este sentido, los geométricos de doble bisel ofrecen una buena representación en los contextos del Neolítico antiguo peninsular nororientales. Destacamos: el nivel Ib de la Cueva de Chaves, donde los diferentes geométricos observados presentan un cierto equilibrio entre el retoque abrupto y el doble bisel, siendo el segundo predominante sobre los segmentos (Cava 2000: 104); la Cueva del Moro de Olvena, donde el conjunto de geométricos está compuesto por 9 segmentos, todos ellos con doble bisel, y un trapecio con retoque abrupto (Utrilla 1995: 62); los niveles V y VI del Abrigo de Forcas II donde el doble bisel aparece como el propio de estos horizontes asociados a la cerámica cardial (Utrilla y Mazo 1997: 353); la Caserna de Sant Pau (Barcelona), donde los trapecios se elaboran mayoritariamente con retoque abrupto y el doble bisel es el propio de los segmentos (5), además de suponer la forma de configuración definitiva en aproximadamente la mitad de los triángulos (Borrel 2008: 41-42); la Draga, asentamiento en el que el retoque abrupto es el mayoritario en los trapecios aunque el doble bisel se documenta también en este tipo de piezas y en los segmentos (Palomo 2000: 204); les Guixeres de Vilobí, donde la situación es similar al ser el retoque abrupto el mejor documentado sobre los trapecios, empleándo-

(4) Esta cronología, si bien concuerda con el registro arqueológico, obliga a abrir la discusión sobre la mayor antigüedad de las dataciones sobre madera vieja (Zilhão 2001).

(5) Este tipo de geométricos parece estar vinculado más a las ocupaciones epicardiales y postcardiales y no tanto a la del neolítico antiguo cardial. se el doble bisel en algunos trapecios y en los triángulos (Mestres 1987: 36). El predominio del doble bisel o, cuanto menos, un equilibrio con el retoque abrupto en las armaduras geométricas parece ser también un rasgo característico en los yacimientos provenzales de Abri Fontbregoua, Le Baratin o Grotte Lombard (Binder 1987; 1991) y del Languedoc (Gazel y Jean Cross) (Binder 1987; Briois 2005).

Estas evidencias encajarían con el proceso de difusión neolítica arrítmica que Guilaine (2000) advirtió a través de los patrones cerámicos del Mediterráneo centro-occidental $\mathrm{y}$, en última instancia, lo que vienen a mostrar son diversos fenómenos colonizadores con orígenes diferentes en momentos cronológicamente paralelos o muy próximos. En este sentido, V. Baldellou y P. Utrilla (1999: 227) han planteado una colonización interior independiente de la vía marítima y llevada a cabo por parte de un grupo neolítico pionero a través de los valles del Segre y del Cinca que conectan con el Midi francés, opción sustentada en las similitudes de los registros líticos de ambas regiones.

De esta manera, los datos con los que se cuenta en la actualidad remiten a dos posibilidades para las comarcas centromeridionales valencianas y, por extensión, para el ámbito mediterráneo de la Península Ibérica. Por una parte, una colonización pionera relacionada con elementos propios de las costas tirrénicas y/o ligures tras la cual se desarrollaría de forma autónoma y autóctona el horizonte cardial en cada ámbito. Esta opción, que cuenta con el apoyo de los datos preliminares de El Barranquet, requerirá en un futuro de un mayor número de contextos arqueológicos y dataciones para consolidarse, aunque bien es cierto que este asentamiento podría representar un unicum dentro de un panorama mucho más amplio y complejo caracterizado por el polimorfismo del primer horizonte neolítico en el cual pudieron intervenir distintos grupos con raíces culturales no siempre homogéneas como se desprende de la dualidad territorial por lo que respecta a la incidencia del doble bisel.

Por otro lado, cabe considerar la opción de una colonización vinculada al horizonte cardial de la región provenzal en la que se mantienen elementos culturales (p.ej. sillon d'impressions) como reflejo de sus raíces centro-mediterráneas. El hecho de que en contextos estratificados la presencia de los elementos de aire ligur aparez- 

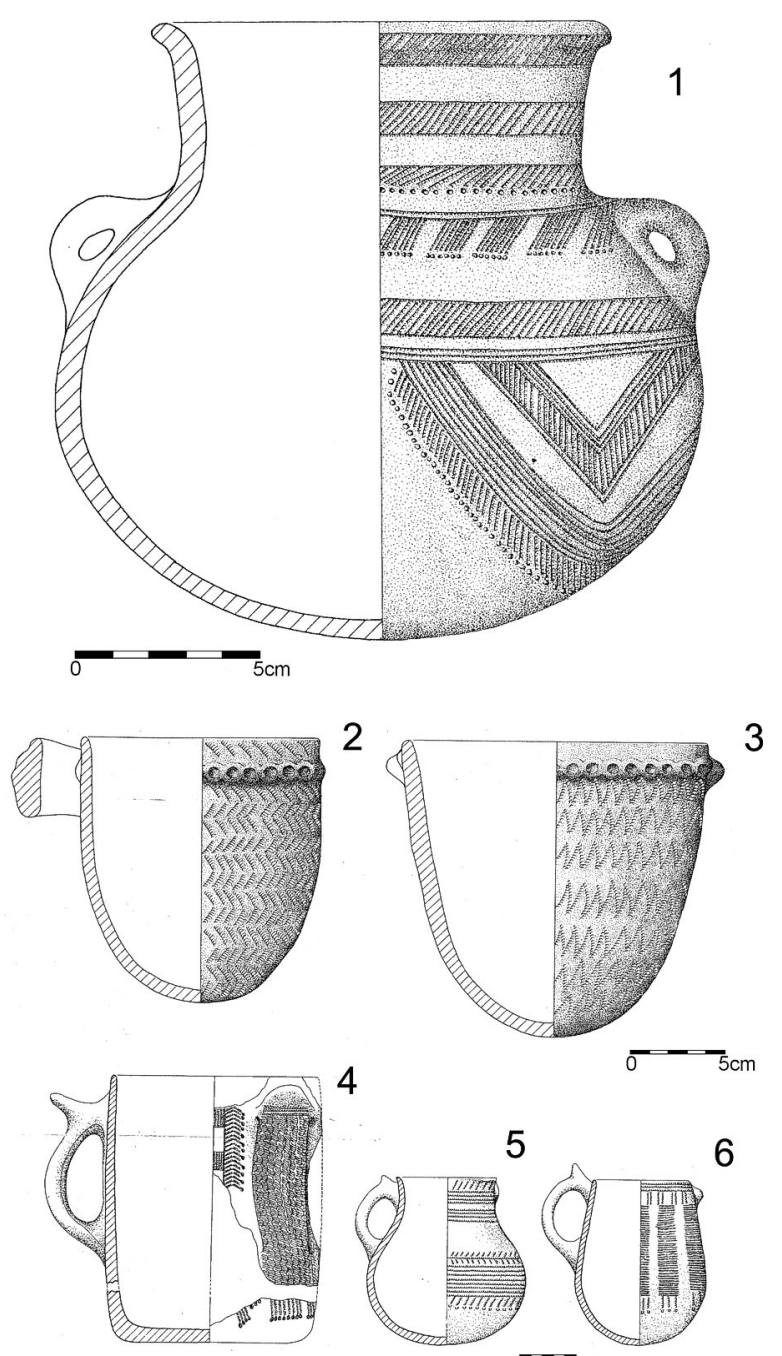

4
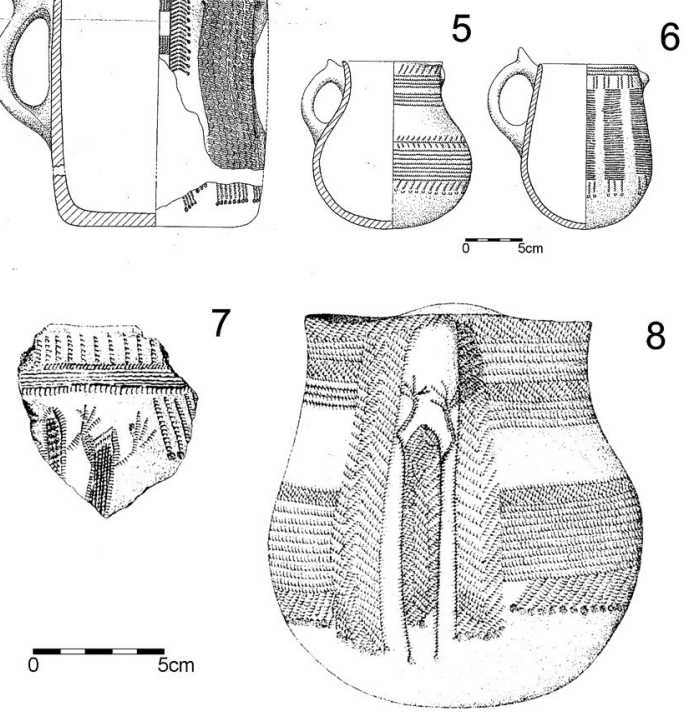

Fig. 9. Cerámica impresa cardial procedente de Cova de l'Or (1-6: Bernabeu 1989; 7-8: Martí y Hernández 1988).

can más o menos englobados dentro de conjuntos típicamente cardiales sustentaría arqueológicamente esta posibilidad, relegando a estos elemen- tos intrusivos a reminiscencias culturales vinculadas a tradiciones previas al cardial zonado que participaron, de un modo u otro, en su configuración. En este mismo sentido, las producciones líticas de los contextos neolíticos iniciales del Levante peninsular presentan evidentes rasgos de similitud con los contextos cardiales clásicos del Languedoc y Provenza occidental y muestran claras divergencias con los contextos tirrénicos.

Sea cual sea la opción válida, queda patente que la neolitización de la fachada oriental de la Península Ibérica está relacionada con un fenómeno de expansión arrítmica $\mathrm{y}$, probablemente, con distintos focos de origen. Tras esta implantación pionera, caracterizada por ocupaciones plurifuncionales y vinculadas al medio natural tendentes a minimizar los riesgos propios de la economía agropastoral no consolidada ni territorial ni demográficamente, cada una de las agrupaciones neolíticas se desarrollará de manera autónoma según se desprende de las diferencias observadas en el registro arqueológico de los distintos núcleos cardiales: grupo valenciano (cuenca del Serpis), grupo catalán (llanuras del Penedés-Vallés con una probable extensión hacia el Gironés y Rosellón) y grupo oscense aragonés que presentan características propias, aunque siempre con elementos comunes que entroncan con el Neolítico cardial franco-ibérico. En consonancia con la independencia de estas zonas cardiales encontraríamos, además de las apuntadas para la tecnología lítica, otras divergencias notables como la presencia en el área valenciana de formas cerámicas exclusivas (asas-pitorro, toneles, vasos geminados y tazas cilíndricas de fondo plano) (Willigen 2004: 476), el extraordinario barroquismo de las decoraciones cerámicas cardiales del área del Serpis, que tiene en la representación de motivos figurados su mejor exponente (Martí y Hernández 1988) o el desarrollo en esta misma región del arte rupestre macroesquemático (Hernández 2003), horizonte artístico propio de las comarcas centromeridionales valencianas $y$ que no encuentra su análogo directo en otras zonas de implantación cardial (Fig. 9).

\section{BIBLIOGRAFÍA}

Ammerman, A.J. y Cavalli-Sforza, L.L. 1973: “A population model for the difusion of early farming in Europe". En C. Renfrew (ed.): The explanation of 
Culture Change: Models in Prehistory. Duckworth. Gloucester Crescend: 343-357.

Ammerman, A.J. y Cavalli-Sforza, L.L. 1984: The Neolithic transition and the genetics of population in Europe. Princeton University Press. Princeton.

Badal, E.; Bernabeu, J.; Buxó, R.; Dupré, M.; Fumanal, M.P.; Guillem, P.; Martínez, R.; Rodrigo, M.J. y Villaverde, V. 1991: "La Cova de les Cendres (Moraira-Teulada)". Guía de las Excursiones de la VIII Reunión Nacional sobre Cuaternario. Universidad de Valencia. Valencia: 21-78.

Baldellou Martínez, V. 1994: "Algunos comentarios sobre el Neolítico en Aragón”. Bolskan, 11: 33-51.

Baldellou, V. y Ramón. N. 1995: "Estudio de los materiales cerámicos neolíticos de Olvena". Bolskan 12: 105-169.

Baldellou, V. y Utrilla, P. 1999: "Le Néolithique en Aragon". XXIVe Congrès Préhistorique de France (Carcassonne, 1994). Le Néolithique du NordOuest méditerranéen: 225-237. Joué-lès-Tours.

Bernabeu Aubán, J. 1982: “La evolución del Neolítico en el País Valenciano. Aportaciones al estudio de las culturas neolíticas en el extremo occidental del Mediterráneo". Revista del Instituto de Estudios Alicantinos 37: 85-137.

Bernabeu Aubán, J. 1989: La tradición cultural de las cerámicas impresas en la zona oriental de la Península Ibérica. Trabajos varios del SIP 86. Diputación Provincial de Valencia. Valencia.

Bernabeu Aubán, J. 1995: “Origen y consolidación de las sociedades agrícolas. El País Valenciano entre el Neolítico y la Edad del Bronce". Actas de las Jornadas de Arqueología (Alfaç del Pí, 1994): 37-60. Valencia.

Bernabeu Aubán, J. 1996: “Indigenismo y migracionismo. Aspectos de la neolitización de la fachada oriental de la Península Ibérica". Trabajos de Prehistoria 53 (2): 37-54.

Bernabeu Aubán, J. 2002: "The social and the symbolic context of Neolithization". El paisaje en el Neolítico mediterráneo. Saguntum-PLAV Extra-5. Universidad de Valencia. Valencia: 209-233.

Bernabeu Aubán, J. 2006: "Una visión actual sobre el origen y difusión del Neolítico en la Península Ibérica. Ca. 5600-5000 cal BC". En O. García y J.E. Aura (coords.): El abric de la Falguera. 8000 años de ocupación humana en la cabecera del río de Alcoi. Ajuntament d'Alcoi. Alcoi: 189-211.

Bernabeu, J.; Fumanal, M. ${ }^{2}$. y Badal, E. 2001: La Cova de les Cendres. Volumen 1: paleogeografía y estratigrafía. Estudis Neolítics, 1. Universitat de València. Valencia.

Bernabeu, J.; Orozco, T. y Díez, A. 2002: "El poblamiento neolítico: desarrollo del paisaje agrario en les valls de 1'Alcoi'. En J.M. Segura y M.S. Hernández (coords.): La Sarga: Arte rupestre y territo- rio. Ajuntament d'Alcoi-Caja de Ahorros del Mediterráneo. Alcoy: 171-184.

Bernabeu, J.; Orozco, T.; Díez, A. y Molina, F.J. 2003: "Mas d'Is (Penàguila, Alicante): Aldeas y recintos monumentales del neolítico inicial en el Valle del Serpis". Trabajos de Prehistoria 60 (2): 39-59.

Bernabeu, J.; Molina, Ll.; Díez, A. y Orozco, T. 2006: "Inequalities and power. Three millennia of Prehistory in mediterranean Spain (5600-2000 cal BC)". En P. Díaz del Río y L. García (coords.): Social Inequality in Iberian Late Prehistory. British Archaeological Reports international series, 1525. Archaeopress. Oxford: 97-116.

Bernabeu, J.; Molina, Ll.; Esquembre, M.A.; Ortega, J.R. y Boronat, J.D. 2009: "La cerámica impresa mediterránea en el origen del Neolítico de la península Ibérica". De Méditerranée et d'ailleurs... Mélanges offerts à Jean Guilaine. Archives d'Écologie Préhistorique. Toulouse: 83-95.

Binder, D. 1987: Le Neolithique Ancien Provençal. Typologie et technologie des outillages lithiques. XXIV Supplement à Gallia Préhistoire, Editions du C.N.R.S. París.

Binder, D. 1989: “Aspects de le néolithisation dans les Aires Padane, Provençale et ligure". En O. Aurenche y J. Cauvin (eds.): Neolithisations, British Archaeological Reports international series, 516. Archaeopress. Oxford: 199-225.

Binder, D. 1995: "Éléments puor la chronologie du Néolithique ancien à céramique imprimée dans le Midi". En J.L. Voruz (dir.): Chronologies néolithiques. De 6000 à 2000 avant notre ère dans le Bassin rhodanien. Actes du Colloque d'Ambérieu-enBugey (1992): 55-65. Genève.

Binder, D. 2000: "Mesolithic and Neolithic Interaction in southern France and northern Italy: new data and current hypotheses". En T.D. Price (ed.): Europe's First Farmers. Cambridge University Press. Vambridge: 117-143.

Binder, D. y Maggi, R. 2001: "Le Neolithique ancien de l'arc liguro-provençal". Bulletin de la Société Préhistorique Française 98 (3): 411-422.

Binder, D.; Brochier, J.E.; Duday, H.; Helmer, D.; Marinval, P.; Thiébault, S. y Wattez, J. 1993: "L'abri Pendimoun à Castellar (Alpes-Maritimes): nouvelles donées sur le complexe culturel de la céramique imprimée méditerranéenne dans son contexte stratigraphique". Gallia Préhistoire 35: 177-251.

Bogucki, P. 2003: "Neolithic dispersals in riverine interior Central Europe". En A. Ammerman y P. Biagi (eds.): The Widening Harvest. The Neolithic Transition in Europe: Looking Back, Looking Forward. Archaeological Institute of America. Boston: 249-272.

Bronk Ramsey, C. 2009: "Bayesian analysis of radiocarbon dates". Radiocarbon 51(1): 337-360. 
Borrel Tena, F. 2008: "La industria lítica tallada del jaciment neolític de la Caserna de Sant Pau". Quarhis época II (4): 36-45.

Brandaglia, M. 2000: "La cultura del Neolítico antico del 'Serotino', le Secche di isola del Giglio". En C. Tozzi y M.C. Weiss (eds.): Il primo popolamento olocenico dell'area corso-toscana. Edizioni ETS. Firenze: 123-132.

Briois, F. 2005: Les industries de pierre taillées néolithiques en Languedoc occidental. Monographies d'Archaeologie Méditerranéenne 20. Lattes.

Cava Almuzara, A. 2000: "La industria lítica del neolítico de Chaves (Huesca)". Salduie 1: 77-164.

Cortell, E. y García, P. 2007: "Nous fragments ceràmics de la Cova de la Sarsa (Boicarent, València) pertanyents a la col-lecció Ponsell del Museu Arqueològic Municipal d' Alcoi”. Recerques del Museu d'Alcoi 16: 61-70.

Ducci, S. 2000: "La neolitizzazione dell'archipielago toscano alcuni dati di recente acquisizione". $L a$ Neolitizzazione tra Oriente e Occidente. Atti Convegno di Udine (1999): 333-340. Udine.

Esquembre, M.A. y Torregrosa, P. 2007: "Cova del Montgó. Catálogo de piezas conservadas en el Museo Arqueológico Provincial de Alicante." En J.A. Soler (ed.): La Cova del Montgó (Xàbia, Alicante). Catálogo de Fondos del MARQ 7. Diputación de Alicante. Alicante: 67-113.

Esquembre, M.A.; Boronat, J.D.; Jover, F.J.; Molina, F.J.; Luján, A.; López, J.; Martínez, R.; Iborra, P.; Ferrer, C.; Ruiz, R.; y Ortega, J.R. 2008: "El yacimiento neolítico del Barranquet (Oliva)". IV Congreso del Neolítico de la Península Ibérica (Alicante, 2006): 183-190. Alicante.

Fontanals, M.; Euba, I.; Oms, F.X. y Morales, J.I. 2008: "El asentamiento litoral al aire libre de El Cavet (Cambrils, Tarragona)". IV Congreso del Neolítico de la Península Ibérica (Alicante, 2006): 168-175. Alicante.

Fugazzola, M.A. y Pessina, A. 1999: "Le village submergé de La Marmotta (Lac Bracciano, Rome)". XIV Congrès de Préhistoire de France (Carcassonne, 1994): Le Néolithique du Nord-ouest méditerranéen: 35-38. Joué-lès-Tours.

Fugazzola Delpino, M.A. 2002: "Les facies a ceramica impresa dell'area medio-tirrenica". En M.A. Fugazzola, A. Pessina y V. Tiné (eds.): Le ceramiche impresse nel Neolitico antico. Italia e Mediterraneo. Istituto Poligrafico e Zecca dello Stato. Roma: 97-116.

Fugazzola, M.A., Negrino, F. Pessina, A. 2000: "Il livelli a ceramica impressa del sito di San Petrino di Rota (Roma)". La Neolitizzazione tra Oriente e Occidente. Atti Convegno di Udine (1999): 365-380. Udine.

Fugazzola, M.A.; Manfredini, A.; Martini. F.; Radi, G.; Sarti, L. y Silvestrini, M. 2003: "Insediementi e strutture neolitiche ed eneolitiche dell'Italia centrale". Atti della XXXV riunione Scientifica del IIPP: 93-112. Firenze.

García Atiénzar, G. 2006. "Abrigos, valles y pastores. Análisis espacial del paisaje pastoril en las tierras centro-meridionales valencianas". En I. Grau (ed.): La Aplicación de los SIG en la Arqueología del Paisaje. Universidad de Alicante: 149-170. Alicante.

García Atiénzar, G. 2009: Territorio Neolítico. Las primeras comunidades campesinas en la fachada oriental de la península Ibérica (ca.5600-2800 cal $B C)$. British Archaeological Reports, International Series 2021. Archaeopress. Oxford.

García Puchol, O. 2005: El proceso de neolitización en la fachada mediterránea de la península Ibérica: Tecnología y tipología de la piedra tallada. British Archaeological Reports international series, 1430. Archaeopress. Oxford.

Grifoni Cremonesi, R. 2001: "Le Néolithique ancien de Toscane et l'archipiel toscan". Bulletin de la Societé Préhistorique Française 98(3): 423-430.

Guilaine, J. 1986. "Le Néolithique ancien en Languedoc et Catalogne". En J.P. Demoule y J. Guilaine (dirs.): Le Néolithique de la France. Hommage à Gerard Bailloud. Paris: 71-82.

Guilaine, J. 2000: "De l'Orient a l'Occident la neolithisation de la Méditerranée. Questions ouvertes". En A. Pessina y G. Muscio (eds.): La Neolitizzazione tra Oriente e Occidente. Atti Convegno di Udine (1999): 11-21. Udine.

Guilaine, J. y Manen, C. 2002: "La ceramica impressa della Francia meridionale". En M.A. Fugazzola, A. Pessina y V. Tiné (eds.): Le ceramiche impresse nel Neolitico antico. Italia e Mediterraneo. Istituto Poligrafico e Zecca dello Stato. Roma: 373-395.

Guilaine, J. y Manen, C. 2007: "From Mesolithic to Early neolithic in the western meditarranean". Proceedings of the British Academy 144: 21-51.

Guilaine, J.; Manen, C. y Vigne, J.D. (dirs.). 2007: Pont de Roque-Haute. Nouveaux regards sur la néolithisation de la France méditerranéenne. Centre d'Anthropologie. Toulouse.

Hernández Pérez, M.S. 2000: "Sobre la religión neolítica. A propósito del arte Macroesquemático". Scripta in honorem Enrique A. Llobregat. Instituto Alicantino Juan Gil-Albert. Alicante: 137-155.

Hernández Pérez, M.S. 2003: "Las imágenes en el Arte Macroesquemático". En T. Tortosa y J.A. Santos (coords.): Arqueología e Iconografía. Indagar en las imágenes. L'Erma di Bretschneider. Roma: 41-58.

Juan-Cabanilles, J. 1984: “El utillaje neolítico de sílex del litoral mediterráneo peninsular. Estudio tipológico-analítico a partir de materiales de Cova de l'Or y de la Sarsa". Saguntum-PLAV 18: 49-101. 
Juan-Cabanilles, J. 1992: "La neolitización de la vertiente mediterránea peninsular. Modelos y problemas". Actas del Congreso Aragón/Litoral Mediterráneo. Intercambios Culturales durante la Prehistoria (Zaragoza, 1990): 255-268. Zaragoza.

Juan-Cabanilles, J. y Martí, B. 2007/2008: "La fase C del epipaleolítico reciente: lugar de encuentro o línea divisoria. Reflexiones en torno a la neolitización en la fachada mediterránea peninsular". Veleia 24-25: 611-628.

Llobregat, E.; Martí, B.; Bernabeu, J.; Villaverde, V.; Gallard, M.D.; Pérez, M.; Acuña, J.D. y Robles, F. 1981: "Cova de les Cendres (Teulada, Alicante): Informe preliminar". Revista del Instituto de Estudios Alicantinos 34: 88-111.

MacClure, S.B. 2007: "Gender, technology, and evolution: cultural inheritance theory and prehistoric potters in Valencia, Spain". American Antiquity 72(3): 485-508.

MacPhail, R.I.; Courty, M.A.; Hasther, J. y Wattez, J. 1997: "The soil micromorphological evidence of domestic occupation and stabling activities". En R. Maggi (dir.): Arene Candide: a functional and environmental assessment of the Holocene sequence. Memorie dell'Istituto Italiano di Paleontologia Umana 5. Roma: 53-88.

Maggi, R. 1997: Arene Candide: A functional and enviromental asseement of the Holocene sequence. Memorie dell'Istituto Italiano di Paleontologia Umana 5. Roma.

Maggi, R. 2002: "La facies e ceramica impressa dell'area ligure". En M.A. Fugazzola, A. Pessina y V. Tiné (ed.): Le ceramiche impresse nel Neolitico antico. Italia e Mediterraneo. Istituto Poligrafico e Zecca dello Stato. Roma: 91-96.

Manen, C. 2000: "Implantation de faciès d'origine italienne au Néolithique ancien l'exemple des sites liguriens du Languedoc". Rencontres meridionales de Préhistoire récente. Troisième session. Éditions Archives d'Ecologie Préhistorique Toulouse: 35-42.

Manen, C. 2002: "Struture et identité des styles céramiques du Néolithique ancien entre Rhône et Ebre". Gallia Préhistoire 44: 121-165.

Manen, C. 2007: "La production céramique de Pont de Roque-Haute: Synthese et comparations". En J. Guilaine, C. Manen y J.D. Vigne (dir.): Pont de Roque-Haute. Nouveaux regards sur la néolithisation de la France Méditerranéenne. Archives d'Ecologie Préhistorique. Toulousse: 151-166.

Manen, C. y Sabatier, P. 2003: "Chronique radiocarbone de la néolithisation en Méditerranée nord-occidentale". Bulletin de la Societé Préhistorique Française 100 (3): 479-504.

Manen, C.; Marchand, G. y Carvalho, A.F. 2007: "Le Néolithique ancien de la péninsule Ibérique: vers une nouvelle évaluation du mirage africain?".
Congrès Préhistorique de France (Avignon, 2004): 133-151. París.

Martí Oliver, B. 2008: “Cuevas, poblados y santuarios neolíticos: una perspectiva mediterránea". IV Congreso del Neolítico de la Península Ibérica (Alicante, 2006): 17-27. Alicante.

Martí, B. y Hernández, M.S. 1988: El Neolític valencià. Art rupestre $i$ cultura material. Servicio de Investigaciones Prehistóricas. Valencia.

Mestres i Mercadé, J. 1987: "La industria lítica en sílex del Neolític antic de les Guixeres de Vilobí". Olerdulae 1-4: 5-41.

Mestres i Mercadé, J. 1992: "Neolitització i territori". En M. Cura-Morera (dir.): Estat de la investigació sobre el Neolític a Catalunya. 9é Col-loqui internacional d'Arqueologia de Puigcerdà (1991). Publicacions del Institut d'Estudis Caretans 17. Andorra: $72-75$.

Oms, F.X. y Morales, J.I. 2008: Cambrils al Neolític. Implantació $i$ desenvolupament de les economies productores al Camp de Tarragona. Ajuntament de Cambrils. Cambrils.

Odietti, G. 1974: "Gli strati neolitici della Grotta Pollera". Atti della XVI riunione scientifica del IIPP (Liguria, 1973): 141-150. Firenze.

Odietti, G. 2002: "Grotta Pollera (Liguria)". En M.A. Fugazzola, A. Pessina y V. Tiné (eds.): Le ceramiche impresse nel Neolitico antico. Italia e Mediterraneo. Istituto Poligrafico e Zecca dello Stato. Roma: 91-96.

Palomo, A. 2000: "La industria lítica tallada de la Draga". En A. Bosch, J. Chinchilla, and J. Tarrús (eds.): El poblat lacustre neolític de la Draga: Excavacions de 1990 a 1998: 197-206. Monografies del Centre d'Arqueologia Subacuàtica de Catalunya 2. Barcelona.

Pessina, A. y Tiné, V. 2008: Archeologia del Neolitico. L'Italia tra VI e IV millenio a.C. Carocci editore. Roma.

Ramón Fernández, N. 2006. La cerámica del Neolítico Antiguo en Aragón. Caesaraugusta 77. Institución Fernando el Católico. Zaragoza.

Roudil, J.L. 1984: "Le Néolithique ancien di Midi de la France et le gisement de Portiragnes (Hérault)". Rapporti tra $i$ Balcani e l'Italia meridionale nell'età neolitica: 91-111. Roma.

Roudil, J.L. 1990: "Cardial et neolithique ancien ligure dans le sud-est de la France". En D. Cahen y M. Otte (eds.): Rubané et Cardial. Eraul 39. Liège: 383-391.

Roudil, J.L. y Soulier, M. 1983: "Le gisement néolithique ancien de Peiro Signado (Portiragnes, Hérault)". XXI Congrès Préhistorique de France 2 (Quercy, 1979): 258-279. París.

Soler Díaz, J.A. 2007: "La Cova Ampla del Montgó y el Museo Arqueológico Provincial de Alicante". En J.A. Soler Díaz (ed.): La Cova del Montgó 
(Xàbia, Alicante). Catálogo de Fondos del MARQ 7. Diputación de Alicante. Alicante: 15-44.

Soler, J.A.; Gómez, O.; García, G. y Roca de Togores, C. e.p. "Sobre el primer horizonte neolítico en la Cova d'En Pardo (Planes, Alicante). Su evaluación desde el registro cerámico".

Tiné, S. 1974: "Arene Candide". Archeologia in Liguria. Scavi e scoperte 1967-1975: 149-158. Génova.

Tiné, S. 1999: Il Neolitico nella Caverna delle Arene Candide (scavi 1972-1977). Bordighera. Génova.

Traverso, A. 2002: "Arene Candide (Liguria)". En M.A. Fugazzola, A. Pessina y V. Tiné (eds.): Le ceramiche impresse nel Neolitico antico. Italia e Mediterraneo. Istituto Poligrafico e Zecca dello Stato. Roma: 91-96.

Utrilla Miranda, M. ${ }^{a}$ P. 1995: "Materiales líticos". Bolskan: Revista de arqueología del Instituto de Estudios Altoaragoneses 12: 49-86.

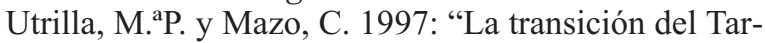
diglaciar al Holoceno en el Alto Aragón: los abrigos de las Forcas (Graus, Huesca)". En P. Bueno y R. de Balbín (coords.): II Congreso de Arqueología Peninsular (Zamora, 1996) 1: 349-366. Zamora.

Vigne, J.-D. y Helmer, D. 1999: "Nouvelles analyses sur les débuts de l'élevage dans le centre et l'ouest méditerranéen". XIV Congrès de Préhistoire de France (Carcassonne, 1994): Le Néolithique du Nord-ouest méditerranéen: 129-146. Joué-lèsTours.
Vigne, J.D. 2007: "Exploitation des animaux et néolithisatoion en Méditerranée nord-occidentale”. En J. Guilaine; C. Manen y J.D. Vigne (dirs.): Pont de Roque-Haute. Nouveaux regards sur la néolithisation de la France Méditerranéenne: 221-301. Archives d'Ecologie Préhistorique. Toulousse.

Vigne, J.D. y Carrère, I. 2007: "Les vértebrés et l'exploitation des ressources animales". En J. Guilaine; C. Manen y J.D. Vigne (dirs.): Pont de Roque-Haute. Nouveaux regards sur la néolithisation de la France Méditerranéenne. Archives d'Ecologie Préhistorique. Toulousse: 181-214.

Willigen, S. van 2004: "Aspects culturels de le néolithisation en Méditerranée occidentale le Cardial e l'Epicardial'. Bulletin de la Société Préhistorique Française 101 (3): 463-495.

Zilhão, J. 1993: "The spread of agro-pastoral economies across Mediterranean Europe. A view fron far West". Journal of Mediterranean Archaeology 6 (1): 5-63.

Zilhão, J. 1997: "Maritime pioneer colonisation in the Early Neolithic of the West Mediterranean. Testing the model against the evidence". Porocilo XXIV: $19-42$.

Zilhão, J. 2001: "Radiocarbon evidence for maritime pioneer colonization al the origins of farming in west Mediterranean Europe". Proceedings of the National Academy of Sciences 98 (24): 1418014185. 